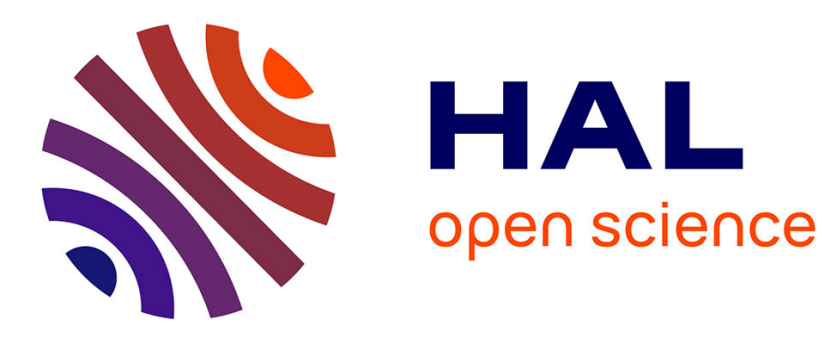

\title{
Quitting and peer effects at work
}

Julie Rosaz, Robert Slonim, Marie Claire Villeval

\section{To cite this version:}

Julie Rosaz, Robert Slonim, Marie Claire Villeval. Quitting and peer effects at work. Labour Economics, 2016, 39, pp. 55-67. 10.1016/j.labeco.2016.02.002 . halshs-01300720

\section{HAL Id: halshs-01300720 \\ https://shs.hal.science/halshs-01300720}

Submitted on 19 Jul 2021

HAL is a multi-disciplinary open access archive for the deposit and dissemination of scientific research documents, whether they are published or not. The documents may come from teaching and research institutions in France or abroad, or from public or private research centers.
L'archive ouverte pluridisciplinaire HAL, est destinée au dépôt et à la diffusion de documents scientifiques de niveau recherche, publiés ou non, émanant des établissements d'enseignement et de recherche français ou étrangers, des laboratoires publics ou privés. 
Published in Labour Economics 39, 55-67, 2016.

\title{
Quitting and Peer Effects at Work
}

\author{
Julie ROSAZ ${ }^{\mathrm{a}}$, Robert SLONIM ${ }^{\mathrm{b}}$, Marie Claire VILLEVAL ${ }^{\mathrm{c}}$
}

\begin{abstract}
This paper studies the influence of peers on the extensive margin of effort at work by means of a real-effort experiment in which subjects have to decide on the intensity of effort and when to stop working. Participants perform a task alone or in the presence of a peer. The feedback on the co-worker's output is manipulated and we vary whether the two workers can communicate. We find that when communication is allowed, the average productivity per unit of time and the quitting time are not increased but the presence of a peer causes workers to stay longer and to quit at more similar times. Peer effects on the extensive margin of effort derive more from a sociability effect, i.e. a reduction of the social distance between co-workers that could make the other's presence more valuable, than from performance or quitting time comparisons.
\end{abstract}

Keywords: Quitting, peer effects, effort, communication, working time, feedback, experiment JEL Codes: C91, D83, J21, J63, J28, J81, M5

${ }^{a}$ University of Montpellier 1, LAMETA, avenue Raymond Dugrand - Site Richter C.S. 79606, F-34960 Montpellier Cedex 2, France. E-mail: rosaz@1ameta.univ-montp1.fr

${ }^{b}$ University of Sydney, Department of Economics, Merewether building, NSW 2006 Sydney, Australia; IZA, Bonn, Germany. Email: robert.slonim@sydney.edu.au

${ }^{\mathrm{c}}$ University of Lyon 2, Lyon, F-69007, France; CNRS, GATE Lyon St Etienne, Ecully, F-69130, France; IZA, Bonn, Germany; Department of Public Finance, University of Innsbruck. GATE: 93, Chemin des Mouilles, 69130 Ecully, France. E-mail: villeval@gate.cnrs.fr

The authors are grateful to R. Zeiliger for programming the experiment and to M. Sidibé for fruitful discussions. Financial support from the EMIR program of the French National Agency for Research (ANR BLAN07-3-185547) is gratefully acknowledged. This research was performed within the framework of the LABEX CORTEX (ANR-11LABX-0042) of Université de Lyon, within the program Investissements d'Avenir (ANR-11-IDEX-007) operated by the French National Research Agency (ANR). 


\section{INTRODUCTION}

Labor economists are increasingly studying the influence of peers on individuals' work effort. ${ }^{1}$

So far, the literature has focused almost exclusively on the impact of peers on individual

productivity, i.e. the intensive margin of effort. However, there are reasons to believe that peers

also influence the amount of time spent working, i.e. the extensive margin. Long working hours

may be viewed by peers as a signal of seriousness. Deviating from this norm may be morally

costly, but observing other workers quitting may reduce these non-pecuniary costs of quitting. ${ }^{2}$

The extensive margin of effort may also be affected by performance comparisons of peers, leading the less able workers either to quit sooner because of discouragement or to work longer

to compensate for more able workers (Eriksson et al., 2009; Fershtman and Gneezy, 2014). ${ }^{3}$

Moreover, the opportunity to socialize with peers may affect when workers quit because peers

can make the work environment more pleasant and because peer's behavior may provide a

salient reference point for the appropriate amount of time to work.

The major contribution of our study is to analyze the impact of peers on the extensive

margin of effort. Specifically, we examine the time spent working and the difference in working

time among peers in a real-effort laboratory experiment. In the experiment, workers are paid

based on the number of mathematical questions answered correctly. After completing an initial

compulsory work time, workers have to decide when to quit. Although our focus is on the

\footnotetext{
${ }^{1}$ Kandel and Lazear (1992) provide an early theoretical study. Bandiera et al. (2005, 2010), Falk and Ichino (2006) and Mas and Moretti (2009) provide prominent examples of empirical tests.

${ }^{2}$ Organizational studies show that both supervisors and co-workers interpret spontaneously passive face-time (i.e. the amount of time an employee is merely seen at work) as informing on the employees' personal traits such as conscientiousness, dedication or initiative (Joyce, 2002; Kossek and Van Dyne, 2008; Elsbach et al. 2010). Studying the time spent volunteering for a charity in which participants could decide when to stop, Linardi and McConnell (2011) found that individuals avoid being the first to stop but are more likely to stop once others have done so.

${ }^{3}$ Eriksson et al. (2009) observed that even when the gap in performance between two competitors is so large that the winner of a tournament is no longer in doubt, the underdogs never quit a competition. In an experiment where students had to run a race either side-by-side or alone, Fershtman and Gneezy (2014) have shown that higher incentives both increase participation and lead to more drop-outs, especially when children run side-by-side.
} 
extensive margin, we also observe the influence of peers on the intensive margin of effort that includes both the number of questions attempted and the number of correct answers per minute. ${ }^{4}$

We focus on whether people work longer alone or in the presence of a peer and on whether co-workers are more likely to have more similar quitting times when they have a choice over the intensity and the duration of the task. Besides examining the extensive margin, our study also varies from previous studies of peer effects by using a cognitively demanding task and using a payment scheme that consists of a fixed wage plus a small piece rate. In particular, we differ from Falk and Ichino (2006) who consider the intensity of effort when workers cannot choose when to quit. Their task has no cognitive requirement (stuffing envelopes); they pay a flat wage and they measure intensity by the number of envelopes stuffed while we take into account also the quality of output (i.e., correct answers) when we consider the intensive margin of effort.

Our second contribution is to examine the channels through which peer effects operate on the extensive margin of effort. The studies on the intensive margin suggest that peer effects can be conveyed by peer pressure, performance comparisons and sociability. Peer pressure is the moral pressure of being judged by one's peers (Kandel and Lazear, 1992). Mas and Moretti (2009) offer evidence of its existence in a field study on supermarket cashiers. Although cashiers are paid a flat wage, the pressure from being observed increases productivity. Peer effects can also operate through performance comparisons by observing others' performance. For example, Falk and Ichino (2006) find that the mean output is higher when people work in pair than when working alone and that the standard deviation of output is smaller within- than between-pairs. Their results are consistent with those of Ichino and Maggi (2000) and with the literature

\footnotetext{
${ }^{4}$ We use a laboratory experiment because it is difficult to identify peer effects with observational data due to the possible presence of correlated effects (Manski, 1993). Indeed, peers may have similar behavior not because they influence each other but because they face similar exogenous environmental characteristics or they have similar utility towards the working time (they have self-selected into the jobs). Laboratory experiments minimize these problems by randomly assigning individuals to treatments and groups.
} 
showing how relative performance feedback influences effort through competitive preferences (e.g. Azmat and Irriberri, 2010; Charness et al., 2013). With performance pay, however, the evidence is mixed. Bandiera et al. (2005) show that under a piece-rate scheme, feedback on coworkers performance negatively affects productivity (see also Barankay, 2012, and Gill and Prowse, 2013), while Beugnot et al. (2013) find positive peer effects in social networks. Finally, sociability may be a vector of peer effects through the reduction in the social distance between employees. For example, Bandiera et al. (2010) find that the presence of a friend working nearby increases the productivity of less able workers, whereas working next to a non-friend co-worker has no impact (see also Guryan et al., 2009).

Our experiment distinguishes between three sources of peer effects on the extensive margin: $i$ ) the combination of peer pressure and comparisons on quitting times, ${ }^{5} i$ ) the combination of peer pressure and comparisons on productivity, and $i i i)$ sociability. First, peer pressure and comparisons on quitting times may impose a stigma related to quitting before others, as well as lower the moral costs of quitting after a peer has quit. Depending on the amount of time a worker would have worked in isolation compared to when their peer quits, the presence of a peer could increase or decrease the amount of time spent working. If a peer works longer than a worker would have worked in isolation, peer pressure and comparisons could lead the worker to work longer to avoid quitting first, whereas if a peer works less than a worker would have worked in isolation, then peer pressure and comparisons could lead the worker to quit soon after his peer quits as this becomes more socially acceptable. Second, the combination of peer pressure and comparisons of productivity could discourage the less able worker, leading him to quit sooner than when working alone. Alternatively, the less able worker may work longer to compensate for

\footnotetext{
${ }^{5}$ Our design does not allow us to tease apart peer pressure (when being observed, like in Mas and Moretti, 2009) and social comparisons (when observing others without being observed) since in all of our peer conditions subjects are always simultaneously being observed by their peer and observing their peer.
} 
being less productive and earning less. Third, the possibility to communicate with peers, beyond observing a peer's performance and quitting decision, may reduce the social distance between co-workers and increase the pleasantness of the time spent working; co-workers may stay longer than when working in isolation, and quit together.

To distinguish these mechanisms, we compare four treatments. In the Single treatment, one subject works alone, so the quitting decision cannot be influenced by, or influence, anyone else. In three peer treatments, two participants start working at the same time. In the No Communication - No Feedback (NCNF) treatment, subjects see if and when their co-participant quits, but cannot observe her output nor communicate with her. By comparing this treatment with the Single treatment, we can identify whether the presence of a co-worker leads the first quitter to stop later and the co-worker to follow rapidly, which would indicate that peer effects on the extensive margin are driven by peer pressure on quitting time and comparisons of quitting time. The No Communication - Feedback (NCF) treatment is identical to NCNF, except that subjects are continuously informed on their co-worker's performance. By comparing this treatment with the previous ones, we can see whether peer effects on the extensive margin, if any, are driven by the combination of peer pressure on performance and comparisons of performance. The Communication - Feedback (CF) treatment is identical to NCF except that subjects can now communicate with each other. Comparing this treatment with the others lets us identify whether peer effects on the extensive margin operate through a more social environment.

Our main measures of the existence of peer effects on the extensive margin of effort are the quitting time and the standard deviation of the quitting times within and between pairs in each peer treatment and hypothetical pairs generated through random matching of subjects from the Single treatment (as in Falk and Ichino 2006). First, in contrast to previous studies, we do not 
find evidence of peer effects on the intensive margin of effort (i.e. the total number of entries per minute nor the number of correct entries per minute). Second, on average subjects did not work longer when they had a co-worker than when working in isolation. Nonetheless, we detect peer effects on the extensive margin in several ways. We find smaller standard deviations in quitting times within pairs in all three of the peer treatments compared to the standard deviation in quitting times in the hypothetical pairs in the Single treatment. Moreover, we find a smaller standard deviation in quitting times within than between pairs in each peer treatment. Both of these effects suggest that peers are leading workers to homogenize the amount of time they choose to work. Moreover, since we detect these effects in all peer conditions, including the no communication and no feedback condition (NCNF), we conclude that peer effects are at least operating through social comparisons of quitting times of a worker's peer.

Comparisons between the three peer treatments help us isolate the nature of peer effects. We do not observe large or significant differences in quitting time and within-pair comparisons between the NCNF and the NCF treatments, suggesting that performance comparisons are not the main driver of peer effects on the extensive margin. On the other hand, we find significant differences in the communication treatment $(\mathrm{CF})$ compared to the two non-communication treatments (NCNF, NCF). When peers can communicate, they are less likely to quit as soon as it is permitted and they are more likely to quit at the same time. The difference between the withinpair and the between-pair standard deviations in quitting time is much larger in CF than in the other treatments. The impact of communication opportunities could be attributed to a reduction in the social distance between peers. Previous literature has shown that reducing social distance affects choices in different contexts (see Bohnet and Frey, 1999; Buchan et al., 2006; Bandiera et al., 2010). In sum, in our experiment peer effects are detected on the extensive margin, and 
operate through both social comparisons of the quitting time of co-workers and the sociability of being able to communicate with a co-worker, but not through comparisons of performance.

The remainder of the paper is organized as follows. Section 2 details the experimental design and the procedures and derives our predictions. Section 3 reports our experimental results. Section 4 discusses these results and concludes.

\section{EXPERIMENTAL DESIGN}

\subsection{Experimental task and treatments}

Our design is between-subjects and consists of four treatments. In the Single (baseline) treatment, subjects perform the task in a room alone. In the three other treatments two workers perform the task in the same room with no one else present. We first describe the features of the experiment that were common to all treatments, and then we introduce the four treatments.

\section{Experimental Task}

The task consists of adding sets of four two-digit numbers and then multiplying the sum by three. The four two-digit numbers are randomly generated and displayed on the computer screen in a column format. To submit a solution, the subject has to enter a numerical answer and validate it. After each entry, the subject is informed whether the answer is correct or incorrect. Then, a new set of four two-digit numbers is displayed on the screen. The computer screen also displays the number of questions answered correctly, and this is updated after each correct response. Aids (e.g., paper, pencil, or calculator) were forbidden in order to increase the concentration necessary to perform the task successfully. The total number of entries and the number of correct answers per minute provide us with two measures of the intensive margin of effort.

To obtain a measure of each subject's ability to perform this task, independent of condition, we included an initial period in which subjects had to perform the task during three minutes. 
Each correct entry pays 10 points with a $50 \%$ chance that the points will be converted into Euros (with 10 points $=€ 0.33$ ). To reduce potential wealth effects due to variation in subject's performance, we determined the outcome at the end of the session. This relatively high piece-rate was used to provide a proxy measure for each worker's maximum output.

The remainder of the session is divided into a compulsory and an optional work time, in which subjects continue to receive addition-multiplication problems. The compulsory work time lasted for 15 minutes followed by an additional 60 minutes in which subjects could quit at any time. The maximum total working time of 75 minutes is made known prior to the beginning of the compulsory task. To end the session, the subject has to press a stop button and then confirm the wish to quit. Once confirmed, the decision is irreversible. After confirmation, the final score is sent electronically to a secretary (located in a different room) who was in charge of payments and the subject is informed to proceed immediately to the payment room.

In addition to potentially getting paid for the initial three minute period, all subjects are paid a combination of a fixed wage of 300 points $(€ 10)$ and a piece-rate of one point for each correct answer. $^{6}$ The fixed wage is paid even if the subject quits immediately after the end of the compulsory time (no one quit before the end of this part). There is no penalty for incorrect entries. The elapsed time from the beginning of each part, the subject's current score and his cumulative earnings for the current part are continuously displayed. We also represented the score visually with a cursor bar increasing in length after every five additional correct entries.

\footnotetext{
${ }^{6}$ This was purposely a modest piece-rate: on average a participant produced 1.85 correct answer per minute in this part of the experiment, corresponding to a piece-rate of approximately $€ 3.50 /$ hour in addition to the $€ 10$ fixed wage. This means that our work environment remains mainly based on a fixed wage to which we add a small bonus based on performance. This is quite representative of many payment schemes in real settings. Moreover, we are interested in studying when participants quit and so we did not want to introduce incentives to stay too long.
} 


\section{Single treatment}

In the Single treatment, only one subject is in the experimental room to avoid any possible peer effect (see Appendix A). This environment corresponds for example to the working environment of a knowledge worker who works in isolation in his office or at home.

\section{Peer treatments}

We investigate three peer treatments in which the instructions, the task and the payment rules are identical to the Single treatment. The key difference with the Single treatment is that two individuals start working at the same time in the room (and no one else). The two subjects receive the same set of problems in the same order on their computers but the numbers are displayed in different orders. Subjects do not receive any feedback on the performance of their co-worker for the initial three-minute task. During the compulsory and optional work time, however, the peer treatments differ from each other in (1) the feedback subjects receive about their co-worker's number of correct entries and (2) the possibility to communicate.

In No Communication - No Feedback (NCNF, hereafter), two desks are arranged in the room and they are separated by a partition (see Appendix B). No oral communication is allowed. Subjects are informed that the microphones on their desks are connected to the experimenter's office and that talking is forbidden. ${ }^{7}$ No information is given on the co-worker's performance. Nonetheless, it is possible that subjects form a belief on their co-worker's effort by hearing the frequency that the co-worker makes clicks (however, this may not be informative of the coworker's performance since more clicks could also mean making more errors) ${ }^{8}$ Each subject is able to see when a co-worker leaves the room, indicating when the co-worker has quit working.

\footnotetext{
${ }^{7}$ In the no-communication peer treatments, no communication was ever heard. A microphone was also present in the Single treatment, but it was not used.

${ }^{8}$ We could not control whether a participant stands up to see his co-worker's score but one can reasonably assume that this was unlikely.
} 
This environment may correspond to open space offices where employees work in cubicles (e.g., in call centers and data entry jobs). This treatment aims to identify the existence of peer effects on quitting through a combination of peer pressure and comparisons in terms of quitting times.

The No Communication - Feedback (NCF, hereafter) treatment is identical to NCNF except that subjects in NCF are given the current number of correct entries of their co-worker. Moreover, the screen displays another cursor bar that increases in length after every five additional correct entries of the co-worker. This treatment aims at identifying the existence of peer effects based on a combination of peer pressure and comparisons in terms of performance.

Finally, the Communication - Feedback (CF, hereafter) treatment is identical to NCF except that communication is allowed without any restriction. Subjects are informed that their conversation is recorded but that it will not be listened to during the experiment. We also removed the partition between the two desks. By allowing communication and subjects to see each other, we have reduced social distance between co-workers. ${ }^{9}$ This treatment corresponds to environments where employees share the same working space and perform similar tasks without working as a team. It allows us to isolate the sociability effect.

\subsection{Behavioral conjectures}

A standard labor supply model assuming that individuals' utility depends on the maximization of their own payoff predicts that there are no peer effects on either the intensive margin of effort or its extensive margin. To maximize payoffs, workers should have no reason to communicate. ${ }^{10}$

\footnotetext{
${ }^{9}$ To the extent that we find differences between $\mathrm{CF}$ and the other peer treatments, we acknowledge that we cannot identify whether the communication, seeing each other, or both explain the differences. Additional treatments that would either (1) allow communication (possibly by a chat box) but leave the partition present or would (2) forbid communication but remove the partition could isolate the unique contribution of each factor. Nonetheless, we are still able to study whether the existence and content of communication have an impact on behavior.

${ }^{10}$ Communication while working takes time and thus, may have a productivity cost. We could have eliminated this cost by allowing communication between work periods (for example, work five minutes, then rest one minute).
} 
Conjecture 1. If subjects have standard preferences, the distribution of productivity and quitting times should be the same across the Single and the three peer treatments.

Now consider potential ways in which the presence of a co-worker affects labor supply. It may influence unobservable variables that change the utility of effort on both its intensive and extensive margins. In this section we only draw conjectures on the impact of peers on the extensive margin of effort. We assume that observing a co-worker working longer may decrease the marginal cost of continuing to work and increase the marginal cost of quitting while the coworker continues to work (to avoid a stigma of being the first to quit), thus causing a worker to quit later than if working alone. On the other hand, once the first worker has quit, the second worker may quit earlier than if working alone if he would have worked longer alone than the time when the co-worker quit. In particular, the first quitter may provide the norm for an acceptable quitting time, and thus provides a reference point so that once he leaves the environment become worse for the co-worker than had he never had a peer. Thus, the presence of a co-worker may cause some workers to work longer than in isolation if they would have quit sooner than the co-worker, and some workers to work less than in isolation if they would have worked longer than when the co-worker quit. The resulting net effect on mean working time could thus be longer, shorter or unaffected by these conflicting influences. Therefore, the presence of a peer has generally an indeterminate effect on the mean working time.

Although the effect of peers on mean working times is indeterminate, the presence of peers should reduce the difference in quitting time within the pairs compared to two workers working in isolation. As already mentioned, one reason is that the first quitter provides a norm for an acceptable quitting time, and thus provides a reference point so that once he leaves the environment becomes worse for the co-worker than had he never had a peer. Another reason is that if peer effects cause co-workers to avoid quitting first, then a worker may have already 
stayed longer than he might have working in isolation when the co-worker quits. So once his peer quits, even if there is no reference point effect, the worker would have quit anyway if working alone, so he will quit soon once the co-worker has departed. We thus conjecture:

Conjecture 2.11 All potential reasons for peer effects lead to a lower within-pair standard deviation of quitting time (based on $\left(a b s\left(t_{1 j}-t_{2 j}\right)\right.$, where $t_{i j}$ represents the quitting time of worker $i$ in pair $j$ ) in the peer treatments than with randomly generated pairs of participants in the Single treatment. The net effect of peers on mean working time is indeterminate and may depend on the mechanism underlying peer effects.

Corollary. The mean difference in quitting time within pairs of co-workers in the peer treatments is smaller than the dispersion between mean quitting times across pairs (based on $\left.\left(\left(t_{1 j}+t_{2 j}\right) / 2\right)\right)$.

We now present the conjectures regarding the three possible mechanisms underlying peer effects on the extensive margin of effort.

One mechanism is the combination of peer pressure and social comparisons in terms of quitting time. If there is a stigma associated with quitting before others (e.g., because it may signal that the individual is not highly motivated or is lazy), a worker who is not willing to be seen as the first to quit will work longer than in isolation. A worker who has observed that his coworker has quit may be more likely to quit just after because the first quitter has given the norm or a reference point and because with the first quitter gone, now the second worker cannot be seen quitting. This mechanism should have the same effect in the three peer treatments.

Conjecture 3. If peer effects on the extensive margin result from a combination of peer pressure and social comparisons in terms of quitting time, then the quitting time should be later for the first quitter in all three peer treatments than in the Single treatment. The within-pair standard deviation of quitting time should be similar across peer treatments and smaller than in the Single treatment.

Another potential mechanism is a combination of peer pressure and social comparisons in terms of performance. If co-workers are differentially productive, then observing this differential

\footnotetext{
${ }^{11}$ Appendix E provides the formal definition of the calculations of the S.D. for the within and between pair differences in the quitting time for conjecture 2 and its corollary.
} 
productivity could affect both workers. First, the less productive worker could be discouraged when receiving feedback showing his relatively poorer performance (as shown by Barankay, 2012, or Gill and Prowse, 2012), and this could cause him to quit earlier than when working in isolation or than in the absence of feedback. On the other hand, the less productive worker, being aware that he is producing less than his co-worker, may be willing to work longer to compensate for his lower productivity. Thus, the less productive worker may quit sooner if discouraged, or longer if wanting to compensate for gaps in performance. We anticipate that the more productive worker will quit later than the less productive worker, ceteris paribus, since he will receive positive information that he is more productive and thus earning a higher payoff per minute. We more importantly anticipate that the more productive worker will quit earlier after the first worker has quit when he has performance information than when he does not since he will have already produced more than his co-worker for certain, and thus will have another reference point from his peer, in terms of earnings, that he will have already surpassed. We thus conjecture:

Conjecture 4. If peer effects on the extensive margin result from a combination of peer pressure and social comparisons in terms of performance, then we anticipate the less productive worker will quit first, the mean quitting time and the within-pair differences in quitting time will be smaller in the peer treatments with performance feedback (NCF and $\mathrm{CF}$ ) than in the treatments without feedback (NCNF and Single treatment).

Finally, peer effects on the extensive margin may be driven by sociability when communication is made possible. Communication makes the working environment more pleasurable by reducing the social distance between co-workers because people can empathize and socialize. This may reduce the non-pecuniary costs of working and favor conformity because it makes the co-worker's presence more valuable. Under this mechanism, the mean working time should be higher and the within-pair standard deviation in quitting time lower in CF than in any other treatment. But it may also happen that communication allows co-workers to coordinate on 
quitting earlier, for example because they discuss the opportunity cost of their time and the relatively low piece rate. Thus, the effect of the mean working time is again indeterminate but there is a clear prediction as regards the lower within-pair standard deviation in quitting time in CF than in the other treatments.

Conjecture 5. If peer effects on the extensive margin result from higher sociability, then co-workers are expected to quit at a more similar time in CF than in the Single treatment and the two peer treatments without communication. The net impact on mean working time is indeterminate.

Obviously, we cannot exclude that several mechanisms drive peer effects simultaneously and in that case, the ranking of peer treatments compared to the Single treatment should allow us to better characterize these peer effects. Table 1 summarizes the relationship between these conjectures and our experimental design to test each conjecture.

(Insert Table 1 about here)

\subsection{Procedures}

The experiment was conducted at the GATE laboratory, Lyon, France, using the Regate software (Zeiliger, 2000). In total, 104 undergraduate students from local business and engineering schools were recruited via ORSEE (Greiner, 2015). In the peer treatments, we were careful to avoid inviting students from the same school to minimize the risk that they knew each other. Twenty-six students participated in each of the four treatments for a total of 65 sessions with 26 Single sessions and 13 sessions in each of the three peer conditions. Sessions lasted on average 75 minutes. The experimenter was the same person for every session.

Upon arrival, participants were required to leave their belongings in the payment room so that no pens, paper, cell phones or calculators would be in the laboratory. Each subject was then walked into the room where the remainder of the experiment occurred. Once in the room, we first asked each subject to provide some basic demographic information. The experimenter then 
read aloud the instructions (see Appendix B). Subjects then completed a quiz to verify their understanding. To avoid any experimenter demand effect (and to avoid the experimenter introducing any peer effect herself), it was made common knowledge that the experimenter left the room permanently. When subjects quit working or when the 75 minute work period was over, subjects were instructed to leave the room and go to the payment room. In the payment room the subjects were invited to write their main reason for quitting.

A secretary who was not aware of the content of the experiment paid each subject in cash. The subjects earned on average $€ 13.85$ ( $€ 14.79$ in the Single treatment, $€ 14.25$ in $C F, € 13.19$ in NCNF and $€ 13.15$ in NCF).

\section{RESULTS}

We first analyze the intensive margin of effort. Then, we focus on the extensive margin of effort by analyzing the quitting time and the within-pair and between-pair standard deviations of the quitting times. Finally, we analyze the individual determinants of quitting behavior.

\subsection{Productivity during the compulsory work time}

In this section we briefly examine the intensive margin of effort (i.e. the score per minute and the total number of entries per minute) during the compulsory 15 minute work time before selection factors are introduced due to quitting behavior.

Table 2 provides descriptive statistics by treatment. The first panel presents the mean score (i.e. the number of correct entries) in the preliminary three-minute part, the compulsory time and the total working time, and the mean number of entries (correct or not) in the compulsory part and during the total working time. The second panel displays the mean score per minute and the mean number of entries per minute. The data are given for all of the subjects as well as disaggregated by the first quitter and the second quitter in the pair. To compare the first and the 
second quitter statistics in the peer treatments with the Single treatment, we generated all 676 (26*26) hypothetical pairs, matching each subject with each of the other subjects in the Single treatment. $^{12}$ In these hypothetical pairs, the worker with the lowest quitting time is defined as the first quitter and the other one as the second quitter. We mention in Table 2 when Mann-Whitney tests indicate significant differences between a peer treatment and the Single treatment. ${ }^{13}$

\section{(Insert Table 2 about here)}

Table 2 shows that the mean score per minute and the mean number of entries per minute during the compulsory working time and during the total working time across all subjects are similar in each peer treatment compared to the Single treatment $(p>0.100)$. The same applies to the first and the second quitters considered separately, except in the CF treatment where the second quitters have a significantly higher productivity than in the Single treatment when considering total working time $(p=0.046)$. In all treatments, scores per minute are lower for those who quit first compared to those who quit second: those who quit first tend to be less able workers as anticipated in conjecture 4.

We next estimate versions of the following OLS model:

$$
\mathrm{y}_{\mathrm{i}, \mathrm{t}}=a+\beta_{\mathrm{t}} \text { Treatment }_{\mathrm{t}}+\beta_{\mathrm{a}} \mathrm{Ability}_{\mathrm{i}}+\beta_{\mathrm{a}, \mathrm{t}} \text { Ability }_{\mathrm{i}}{ }^{*} \text { Treatment }_{\mathrm{t}}+\beta_{g} \text { Male }_{\mathrm{i}}+\varepsilon_{\mathrm{i}, \mathrm{t}}
$$

where $y_{i, t}$ is either subject $i$ 's mean number of correct entries per minute or mean number of correct plus incorrect entries per minute during the compulsory period in treatment $t$, "Treatment" is a dummy variable for the treatment (Single, NCNF, NCF or CF), "Ability" is

\footnotetext{
${ }^{12}$ By generating $26 * 26$ pairs instead of $26 * 25$, we allow people to be matched sometimes with themselves. This captures the idea that in real life people may be matched with someone exactly similar to them and this is a conservative choice. Indeed, for $1 / 26$ of the pairs there is no within-pair difference in quitting time; therefore, the difference observed in the within-pair dispersion of quitting time between the Single treatment and the peer treatments may be underestimated.

${ }^{13}$ Throughout the paper, the $p$-values are from two-tailed Mann-Whitney tests, unless specified otherwise. Each pair of co-workers (each worker in the Single treatment) gives one independent observation. For the non-parametric tests for to the first (second) quitters, we compare the first (second) quitters in a peer treatment with all of the single subjects in the Single treatment (we do not use the hypothetical pairs for these tests).
} 
subject $i$ 's score per minute during the initial 3 minute period, and "Ability ${ }_{\mathrm{i}}{ }^{*}$ Treatment $\mathrm{t}_{\mathrm{t}}$ " is the interaction of Ability by Treatment (to investigate whether the peer treatments have a distinct effect on workers with higher or lower ability). We also control for gender effects. In columns (1), (2), (4) and (5), the reference is the Single treatment, while in columns (3) and (6) we exclude the Single treatment and the reference is NCNF. In columns (1) and (4), an independent variable indicates whether the treatment is a peer treatment, while in columns (2), (3), (5) and (6) we replace the peer treatment variable with dummy variables for each peer treatment. Finally, column (7) only considers the CF treatment and includes two dummy variables that indicate whether the subject talked with his peer about the task (giving advice or explaining how he is proceeding) or discussed unrelated topics. Because subjects work in pairs in the treatment conditions, we cluster standard errors at the pair level in all regressions. Table 3 presents the results of the estimates.

\section{(Insert Table 3 about here)}

The estimates reported in Table 3 confirm largely the statistics displayed in Table 2. While directionally the peer treatments positively affect the score per minute during the compulsory period, in no condition does the effect reach significance ( $p>0.20$ in all regressions). ${ }^{14}$ In equivalent regressions in which we replaced the score per minute with the total number of entries per minute (see Table D2 in Appendix D), the treatment variables are not significant either.

Not surprisingly, ability has a highly significant impact on the score per minute but there is no significant difference in the effect of ability across treatments when treatments are compared to the Single treatment (see columns (4) and (5)). When considering only the peer treatments, the score per minute is lower in NCF than in NCNF but the negative effect of feedback on the peer's

\footnotetext{
${ }^{14}$ Removing the ability variable from models (1) to (3) changes the sign of some treatment variables but does not affect the level of significance of these variables (see Table D1 in Appendix D).
} 
score in this treatment affects only the less able subjects (see column (6)). We find no such effect when the dependent variable is the total number of entries per minute. This suggests that feedback does not demotivate the less able workers but it makes them less successful, perhaps because they become more distracted or nervous. Interestingly, this effect vanishes when communication is added to feedback. This may be because communication allows the workers to exchange advice in the CF treatment. Indeed, the regression in column (7) indicates a significant positive effect on productivity of talking about the task and a negative effect of talking about unrelated topics, provided subjects started talking during the compulsory working period. ${ }^{15}$ The combination of these two effects may explain why the overall productivity during the compulsory period is not higher in CF than the other treatments.

Examining the score per minute in the optional period conditional on keeping working after the compulsory time (see Table D3 in Appendix D), we find qualitatively similar results, except that the type of communication in CF no longer has an impact.

To sum up, there is very little evidence of an effect of the presence of a peer on the intensive margin of effort during the compulsory period when measured either by output or by attempts per minute, in contrast with previous studies on peer effects at work. The negative effect of feedback on less able workers in NCF is counterbalanced by the introduction of communication in CF. These findings differ from those of Falk and Ichino (2006) or Mas and Moretti (2009) who

\footnotetext{
${ }^{15}$ All the subjects talked with each other during work time. Six pairs (46\%) exchanged information on how to do the task. For example, "First I write the sum and then I write the multiplication's result and cancel the sum's result. It is faster like that." Three of these six pairs exchanged advice during the initial three-minute task. No group exchanged advice after the compulsory 15-minutes, suggesting that any gains in productivity due to communicating ideas on the task should have been primarily realized by the compulsory time. In addition, seven of the 13 pairs (54\%) spoke primarily about topics entirely unrelated to the experiment. For example, "Where do you come from?" Five pairs talk about both advice and unrelated topics, 2 pairs only talk about how to solve the problem and the difficulty of the task, 5 pairs talk only about the difficulty of the task. All the groups spoke about the difficulty of the task. For example, "I am so bad in mental calculations," and "I have not done calculations since primary school." No pair talked about when to quit or about coordinating on quitting.
} 
find that the presence of peers raises the productivity of the less able workers. ${ }^{16}$ They are more consistent with Barankay (2012) and Gill and Prowse (2012) who have identified a discouragement effect of relative feedback. These differences may be due to the higher concentration required by our task compared to that required to stuff envelopes or work as a cashier, which may lower attention to others. They may also be due to using a piece-rate instead of a remuneration independent of output as in Falk and Ichino (2006) or Mas and Moretti (2009), which may focus more attention on one's own outcome. A possible explanation of the negative effect of feedback on less able subjects in NCF is that communication is not permitted, which may create an additional frustration (although the number of entries is not different); in contrast, in Falk and Ichino (2006) relative feedback and communication cannot be separated. Finally, it is also possible that when people have to decide on both the intensity and the duration of work, peer effects are conveyed more through the duration of work than through productivity.

\subsection{Peer effects on the extensive margin of effort}

The analysis of peer effects on the extensive margin is based, firstly, on the mean quitting times across treatments. Secondly, we compare standard deviations in quitting time within pairs and between pairs, both within each treatment and across treatments. Indeed, our conjectures on peer effects predict that the presence of peers in all treatments will reduce within-pair quitting time differences relative to the Single treatment and relative to the mean quitting times between pairs, and this effect will be stronger when performance information is included and strongest when communication is further included (see Table 1 above).

\subsubsection{Quitting time}

The third panel of Table 2 focuses on the extensive margin of effort and shows the mean quitting

\footnotetext{
${ }^{16}$ Sample size is unlikely to explain the difference in results since we examine 39 pairs across our three peer treatments whereas Falk and Ichino (2006) examined 8 pairs, except if both studies are underpowered.
} 
time in minutes and the percentages of workers quitting as soon as allowed, at the maximum allowed working time, and at the same time as the co-worker (i.e., within a minute). Table 2 indicates no significant difference in the mean quitting time between any peer treatment and the Single treatment among all subjects ( $p=0.365$ for NCNF, 0.245 for NCF, and 0.493 for CF).

The picture differs when we observe the first and the second quitters separately. First quitters quit earlier in NCNF and NCF than in the Single treatment $(p=0.046$ for NCNF and $p=0.022$ for $\mathrm{NCF}$ ), while second quitters' mean quitting time is not significantly different between any peer treatment and the Single treatment ( $p=0.602$ for NCNF, $p=0.688$ for NCF and $p=0.148$ for CF). Comparing CF with the other peer treatments reveals that the mean quitting time across all subjects is later in CF than in both NCNF $(p=0.085)$ and NCF $(p=0.054)$. The first quitter also quits later in $\mathrm{CF}$ than in $\mathrm{NCF}$ ( $p=0.043)$, but there is no significant difference in the quitting time of the first quitter in $\mathrm{CF}$ and $\mathrm{NCNF}(p=0.317)$. The second quitter quits no later in $\mathrm{CF}$ than in any other treatment ( $p=0.317$ compared with NCNF, $p=0.249$ with $\mathrm{NCF}$ ). Part of the difference between $\mathrm{CF}$ and NCF stems from the fact that when there is feedback on the co-worker's performance but communication is not allowed (in NCF), a higher fraction of subjects quit as soon as permitted ( $p=0.021$ ), whereas when communication is allowed (in CF), pair members are more likely to quit together ( $p=0.023$ comparing CF with either NCF or NCNF) and later.

These results are corroborated by Figures $1 \mathrm{a}$ and $1 \mathrm{~b}$ that plot the cumulative frequency of the quitting times of the first and second quitters, respectively. These figures show that the profile of quitting times differs somewhat across treatments. In NCNF and NCF, a substantial amount of quitting occurs in the first several minutes after the compulsory work period is completed (see Figure 1a). Within three minutes after the compulsory work period had finished, over $50 \%$ of first quitters had quit in NCNF and NCF whereas less than $25 \%$ had quit in the 
Single and CF treatments. Forbidding communication when there are two co-workers may have a crowding-out effect on intrinsic motivation. ${ }^{17}$

\section{(Insert Fig. $1 a$ and $1 b$ about here)}

The previous analysis suggests that the quitting decision may be decomposed into two elements: (1) the decision to keep working or to quit as soon as permitted, and conditional on keeping working, (2) the decision on how long to stay at work. We have thus estimated a twostep Heckman model to account for a possible selection bias in the decision to keep working. The selection equation is estimated using a probit model in which the dependent variable is the decision to continue to work after 15 minutes; the independent variables include each treatment (the Single treatment is the reference), ability per minute in the three-minute initial part and gender (equation (2)). The regression equation is an OLS model in which the dependent variable is the final quitting time, conditional on deciding to keep working after the compulsory work time (equation (3)). The regressors are the same as in the selection equation except that we include the Inverse of the Mill's Ratio (IMR) calculated from the first equation to correct for a potential selection bias. In order to disentangle the indirect effects of variables via selectivity from their direct effect on working time, we exclude the "ability" variable that influences significantly the decision to keep working; thanks to this instrument, we can identify the model. ${ }^{18}$

\footnotetext{
${ }^{17}$ The reasons for quitting can be classified in four main categories: Insufficient incentives (gains were too small for the time spent), income-targeting (the subject earned what he expected or he earned enough money for today), taskrelated reasons (the subject didn't like the problems, the task was too boring) and ability-related reasons (the subject was tired, it took too long to solve a problem, or the subject started to make too many mistakes). Descriptive statistics on the distribution of these reasons can be found in Appendix C. The main difference between NCF and the other treatments is not related to the working environment, but to the insufficient level of incentives. This reason is evoked $61.90 \%$ of the time in NCNF, $68.42 \%$ in NCF, $42.11 \%$ in CF and $42.84 \%$ in the Single treatment. This may suggest that in an environment where communication is not permitted, people need more monetary incentives to provide the same level of effort.

${ }^{18}$ The first stage of the model we estimate is:

$C_{i}^{*}=\gamma_{i} Z+\varepsilon_{i}$, with $C_{i, t}=1$ if $C_{i, t} *>0$ and $\mathrm{C}_{\mathrm{i}, t}=0$ otherwise

where $\mathrm{C}$ is the probability to continue to work, $\mathrm{Z}$ is the vector of independent variables and $\varepsilon$ is the normally distributed error term. The second stage of the model is:
} 
Table 4 reports the marginal effects from the selection equation in column (1), the estimates of the conditional quitting time across all subjects in column (2), for the first quitters in column (3) and for the second quitters in column (4), with the Single treatment taken as the reference. In columns (3) and (4), we use for the Single treatment the data from the hypothetical matched pairs. Finally, we report the estimates of the second equation for the first quitters (model (5)) and the second quitters (model (6)) when the whole analysis includes only the peer treatments, with $\mathrm{NCNF}$ as the reference category. Standard errors are clustered at the pair level. ${ }^{19}$

\section{(Insert Table 4 about here)}

Table 4 indicates that compared to the Single treatment, subjects in CF are $12 \%$ more likely to decide to keep working at the end of the compulsory work time. Conditional on this decision, the quitting time does not differ across treatments, except that the first quitters work longer in $\mathrm{CF}$ than in NCNF.

\subsubsection{Within-pair and between-pair heterogeneity in quitting time}

To have a more precise view of peer effects on quitting time, we next explore within-pair and between-pair heterogeneity. We start with the mean within-pair difference in quitting time.

Descriptive statistics in the third panel of Table 2 indicate that this difference is smaller in CF than in the Single treatment ( $p=0.034)$, while it is null between any of the other peer treatments and the Single treatment ( $p=0.570$ for NCNF and 0.711 for NCF). Consistently, the proportion of

$$
T_{i}=\delta_{i} X+\rho \sigma_{i} \frac{\phi\left(\gamma_{i} Z\right)}{1-\Phi\left(\gamma_{i} Z\right)}, \text { observed only if } \mathrm{C}_{\mathrm{i}, \mathrm{t}}=1
$$

where $\mathrm{T}$ is the conditional expectation of final quitting time, $\mathrm{X}$ is the vector of independent variables, $\rho$ is the correlation between the unobserved determinants of the probability to keep working $\varepsilon$ and the unobserved determinants of the final quitting time, $\sigma$ is the standard deviation of the unobserved determinants of the final quitting time, and the ratio is the Inverse of the Mill's Ratio evaluated at $\gamma_{i} z$ that relates the probability density

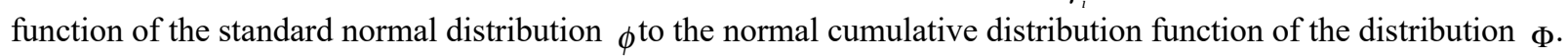

${ }^{19}$ For the Single treatment in columns (3) and (4), standard errors are clustered at the individual level since a subject cannot have influenced another pair member but each individual is observed in several hypothetical pairs. 
pairs in which workers quit at the same time is higher in CF than in the Single treatment $(p<0.001)$. This indicates the existence of peer effects on the extensive margin when communication is permitted. The within-pair difference is lower in CF than in the other peer treatments, directionally consistent with conjecture 5, but it fails to reach a standard level of significance $(p=0.125)$. Conditional on having a partner not quitting as soon as permitted, the within-pair difference in NCF goes down from 22.85 to 5.39 minutes (6 observations), while it is stable in CF (12.23 minutes instead of 13.41) and in NCNF (17.55 minutes instead of 21.67); this suggests some peer effects in NCF but only for a few subjects.

We next turn to a three-step analysis of standard deviations (S.D. hereafter). The first step examines whether the quitting time is more similar within than between pairs in each peer treatment (see Falk and Ichino, 2006). In NCNF, the mean within-pair S.D. is 15 minutes and 19 seconds while the mean between-pair S.D. is 20 minutes and 47 seconds. The corresponding values are 16 minutes and 9 seconds and 20 minutes and 28 seconds, respectively, in the NCF treatment. The difference between within- and between-pair quitting times is larger when communication is allowed; in CF, the mean within-pair S.D. is 9 minutes and 29 seconds while the mean between-pair S.D. is 20 minutes and 33 seconds. The between-pair S.D. is quite similar across all three peer treatments, whereas the within-pair S.D. is much lower when communication is allowed.

The second step compares the differences in the quitting time within pairs and between pairs between the Single and the peer treatments. If peer effects occur, we expect that the within-pair S.D. will be lower in the peer treatments than in hypothetical pairs generated by the random allocation of the subjects in the Single treatment. We also expect that the S.D. between pairs will be higher in the peer treatments than in the hypothetical Single treatment pairs. To test this, we 
generate 30,000 configurations of 13 hypothetical pairs formed with the 26 participants of the Single treatment (see procedures in Appendix E).$^{20}$ Figure 2a (2b, respectively) plots the Kernel density of the mean within-pair (between-pair) S.D. for the 30,000 configurations and displays for each peer treatment the mean value of the within-pair (between-pair) S.D. that is represented by a vertical line (note that in $2 \mathrm{~b}$ the $\mathrm{CF}$ line is overlapping with the NCF line). These Figures show that in each peer treatment the within-pair S.D. lies on the left of the within-pair S.D. distribution for the hypothetical pairs in the Single treatment, while the between-pair S.D. lies on the right of the distribution. The difference is striking when communication is allowed. In CF, the mean within-pair S.D. (between-pair, respectively) is lower than 100\% (99.8\%) of the observations for the hypothetical configurations. For NCNF, the corresponding percentages are $98.40 \%$ and $99.81 \%$; for NCF, they are $97.95 \%$ and $99.81 \%$.

Finally, the third step combines the two previous analyses to compare the difference between the between-pair S.D. and the within-pair S.D. in each peer treatment with the difference computed for the hypothetical pairs in the Single treatment. This comparison thus measures the difference-in-difference between each peer treatment and the Single treatment. ${ }^{21}$ Figure 2c displays the Kernel density of this difference for the 30,000 configurations and displays for each peer treatment the mean value of the difference (between-pair S.D. minus within-pair S.D.) that is represented by a vertical line. The difference in heterogeneity between and within pairs is much larger in the peer treatments than in the Single treatment, especially so in CF $(p<0.001)$.

$$
\text { (Insert Fig. } 2 a, 2 b \text { and } 2 c \text { about here) }
$$

To sum up: when communication is allowed, peers are less likely to quit as soon as

\footnotetext{
${ }^{20}$ In the rest of the paper, we have generated hypothetical pairs in the Single treatment by simply matching artificially each participant with each participant in this treatment $(26 * 26)$.

${ }^{21}$ An advantage is that it controls implicitly for possible biases due to unobserved variables common to the peer and the Single treatments. It also avoids possible biases when comparing the Single and the peer treatments that could result from differences between the subjects across the treatment groups.
} 
permitted compared to subjects working in the Single treatment. The difference in quitting time is smaller within pairs than between pairs in all treatments. The difference in quitting time is also smaller within pairs and larger between pairs in the peer treatments than in hypothetical pairs in the Single treatment. Finally, the difference-in-difference in quitting time between vs. within pairs is much larger in the peer treatments than in the Single treatment. This analysis leads to the following result that rejects Conjecture 1 and supports Conjecture 2 and its corollary.

Result 1. Peer effects affect the extensive margin of effort by influencing the quitting decision, mainly by postponing the quitting decision of the first quitter when communication is allowed.

\subsection{Determinants of the continuing to work vs. quitting decision}

We finally examine the determinants of the decision to continue or quit working at any time $t$ in order to better understand which mechanisms drive peer effects. We estimate a non-parametric

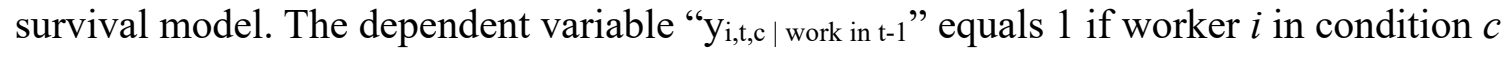
chooses to continue to work at minute $t$ and equals 0 otherwise, conditional on worker $i$ working at time $t-1$. The observed hazard rates do not fit any conventional hazard model function (e.g., exponential); Figure 1e in Appendix F based on Kaplan-Meier survival estimates shows nonmonotonicity in the hazard rates (e.g., there is a high rate of quitting in the first ten minutes, then a fairly low rate of quitting over the next half of the optional work time, followed by another high rate of quitting closer to the end of the optional work time). We thus let the effect of time on the decision to continue working at any minute be non-monotonic. ${ }^{22}$ Our regression models show the effect of time on survival using "minute" and "minute-squared" variables. We estimated higher order time effects (e.g., "minute-cubed") but found that no higher orders effects were significant. We thus estimate several versions of the following basic model:

\footnotetext{
${ }^{22}$ We exclude the final four minutes (72-75) since at this time, workers may quit for reasons associated with the impending forced ending time at 75 minutes.
} 


$$
\mathrm{y}_{\mathrm{i}, \mathrm{t}, \mathrm{c}} \mid \text { work in } \mathrm{t}-\mathrm{l}=f\left(\text { minute, }_{\text {minute }}{ }^{2} \text {, ability, partner_work } \mathrm{t}_{\mathrm{t}-1, \mathrm{c}} \text {, partner_not_work } \mathrm{t}_{\mathrm{t}-1, \mathrm{c}}, \mathrm{)}\right.
$$

where "minute" and "minute-squared" are the time in minutes during the voluntary period, "ability" equals the workers score per minute during the initial period, "partner_work dummy variable equal to 1 if the subject's partner was working in condition $c$ at time $t$ - 1 , and

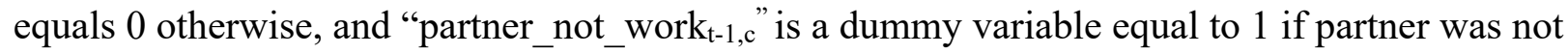
working, and equals 0 otherwise. ${ }^{23}$ "Partner_work $\mathrm{t}_{\mathrm{t}-1, \mathrm{c}}$ " and "partner_not_work $\mathrm{t}-1, \mathrm{c}$ " respectively measure the effect of the peer treatment when a subject's peer is still working or not, compared to the Single condition. ${ }^{24} \mathrm{We}$ are also interested in whether workers are more or less likely to keep working when their co-worker is present compared to when he has left. To address this question, the last row of the Table reports whether the effect of partner working and partner not working have significantly different effects; if the effects are the same, we can attribute any significance to the treatment. Finally, since the choice subjects had each minute while working was to either continue or quit, we can estimate the survival models with discrete choice probit models (Singer and Willett, 1993). We report in Table 5 standard errors clustered at the pair level. $^{25}$

\section{(insert Table 5 about here)}

Across virtually all models "minute" has a positive significant effect on continuing to work $(p<0.05)$ while "minute-squared" has a negative effect $(p<0.05)$, which is consistent with the

\footnotetext{
${ }^{23}$ We also estimated models where we included the interaction of condition by minute as well as ability by condition. We did not find any significant interaction effects and thus do not report these estimates.

${ }^{24}$ Note that we cannot estimate the effect of "treatmentt-1,c", "partner_workt-1,c" and "partner_not_workt-1,c" since they are perfectly multi-collinear. We can thus only estimate the effect of two of these variables, and we found the interpretation of the model easier by including "partner_workt-1,c" and "partner_not_workt-1,c". The results are identical no matter which two of these three variables we include. We acknowledge, however, that the variables "partner working" and "partner not working" are not random (i's working decision is influenced by j's decision to quit, but j's decision to quit is also influenced by i's willingness to continue to work). Unfortunately, we do not have a variable to instrument the peer's decision to quit.

${ }^{25} \mathrm{We}$ also ran the identical models clustering standard errors at the individual level. The qualitative conclusions are similar clustering at the pair or individual level.
} 
non-monotonicity discussed above. Comparing NCNF with the Single treatment, column 1 shows that there is no treatment difference in the decision to continue working while the coworker is still working. However, once the co-worker leaves then the subject is marginally significantly more likely to quit in NCNF than in the Single treatment. Column 2 shows no significant difference between the Single and the NCF treatments. Column 3 compares the Single and the CF treatments and shows stark contrast to the no communication peer treatments. Indeed, when subjects can communicate and both co-workers are working, they are significantly more likely to continue working than subjects in the Single treatment. Column 4 pools all treatments in a single model. The results are qualitatively similar to those reported for the pairwise comparisons. $^{26}$

To sum up: First, compared to the Single treatment, when his co-worker has quit there is a marginally higher likelihood at every subsequent minute that a worker will quit. This is observed in NCNF, which supports Conjecture 3, but not in NCF, which does not support Conjecture 4. Second, this effect is not accompanied by an increased motivation to work longer when the coworker is still present in the no-communication peer treatments. This suggests that the loss of a peer is worse than having never had one in terms of the decision to continue to work. In contrast when communication is allowed, there is a positive effect of the presence of a peer on the motivation to work longer. This leads to the following results that support our conjecture 5 .

Result 2. Allowing communication in a peer treatment affects positively the extensive margin of effort, supporting the hypothesis that a more sociable environment provided by communication reduces social distance between co-workers and explains the mutual influence of co-workers on their quitting decision.

\footnotetext{
${ }^{26}$ We have also estimated the models in Table 5 without the "partner working/not working" by treatment variables, but with treatment dummies (see Table G1 in Appendix G). The results are consistent with those reported in Table 5. In particular, the quitting time in $\mathrm{CF}$ is significantly later than in the two non-communication (NCNF and NCF) treatments; on average, and unconditional on whether the partner is still working, at any given minute peers in $\mathrm{CF}$ were 1 percent more likely to keep working than peers in either of the no-communication treatments.
} 
Result 3. Forbidding communication leads to earlier quitting of the first quitter, which marginally reduces the motivation of the second quitter to keep working.

\section{DISCUSSION AND CONCLUSION}

In this paper, we have studied the influence of peers on the duration of voluntary working time when workers can choose both the intensity of their effort and its duration, while most of the previous literature has focused on the intensive margin of effort. In contrast with this literature, we find that having a co-worker has limited effects on the intensive margin (productivity) during the compulsory working time. This may be due to several differences between study designs such as (a) the amount of concentration needed, (b) the presence or absence of a piece rate in addition to a fixed wage, or (c) that peer influence will be more on the extensive margin than the intensive margin of effort when workers choose both the intensity of effort and its duration. The precise identification of the sources of the differences in the intensive margin with previous literature is left for further research.

Our main contribution focused on the influence of peers on the extensive margin of effort. Our results indicate limited evidence of peer effects on the average time that subjects chose to quit working, despite having significant effects on the individual decision to quit. In particular, the average working time is not significantly greater in the peer treatments than in the Single treatment. However, our analysis of within-pair and between-pair standard deviations in quitting

time shows that there is less heterogeneity in the quitting time within pairs than between pairs in the peer treatments compared to the Single treatment. This similar quitting time in all peer treatments is consistent with peer effects operating through a combination of peer pressure and social comparisons of the quitting time that was present in all peer treatments. In contrast, we find no differences in peer effects when performance information of peers is provided, which 
rejects the conjecture, at least in the current context, that peer effects on the extensive margin operate through peer pressure and social comparisons on relative performance.

Our major contribution is showing that the peer effects are strongest when workers have the possibility to communicate with each other. When subjects were allowed to communicate, they were more likely to work beyond the compulsory period, to work longer if they were the first quitter in the pair, and to quit at the same time as their co-worker if they were the second quitter. Our interpretation is that communication reduces the social distance between peers, making the other person more valuable and his behavior more meaningful. This higher sociability generates positive peer effects. However, when communication was prohibited, more first quitters quit as soon as permitted. The lack of communication appears to create an uncomfortable environment.

Our results, especially those related to the importance of communication, are consistent with the findings of Bandiera et al. (2010) who have shown that when workers work alongside friends, the overall output is not improved but high productivity workers work less hard while low productivity workers work harder. Here, co-workers behave more similarly not in terms of work intensity but in terms of working time when they can communicate. This suggests that the same mechanism can be at work: people value more the behavior of somebody they feel closer to than the behavior of somebody they do not know or that they cannot even see except when quitting. Of course, communication could have had the opposite effect if workers took this opportunity to coordinate on early quitting, but the positive effect appears to be stronger possibly because quitting would interrupt a presence that people seem to enjoy.

Being one of the first studies to examine the extensive margin of peer effects on work effort, replication studies are important to understand the generality of our results. Further experiments could test whether peer pressure through social comparisons of when a co-worker quits could be 
examined by not letting workers know when a co-worker quits. New experiments could also test whether the sociability that drives our largest peer effects on quitting would differ in a less cognitively demanding task or in a flat wage environment. In a simple task that does not require concentration, people would not have to refrain from talking to preserve their productivity. Our conjecture is that peer effects should be higher in a less cognitively demanding task than in our environment. We formulate the same conjecture for a working environment paying workers a flat wage. If wages are independent of performance, we conjecture that people would communicate more and sociability would be reinforced. These conjectures suggest that our current design is very conservative and might underestimate the importance of peer effects on quitting. Another interesting extension would be to introduce competition between co-workers to explore the link between competition and peer effects on the extensive margin of effort. Indeed, overwork and binge working in companies have become an important issue for human resource managers. This usually occurs in highly competitive high-stake work environments where workers may constantly feel compared to co-workers. We could also explore whether a less strong intervention than fully forbidding talking in the peer treatments without communication would modify our findings and to what extent quitting time is affected by how subjects perceive their co-worker. Another extension could test a treatment with communication but with no feedback on the coworker's performance.

Although we are careful not to extrapolate our results to external settings too broadly, they suggest that the direction of peer effects on the extensive margin of effort depends highly on the facilitation of human interactions. Offering a more convivial and interactive working environment may benefit companies by generating positive peer effects on quitting times. 


\section{REFERENCES}

Azmat, G. and N. Iriberri (2010), "The Importance of Relative Performance Feedback Information: Evidence from a Natural Experiment using High-school Students," Journal of Public Economics, 94 (7-8), 435-452.

Bandiera O., I. Barankay I., and I. Rasul (2005). "Social Preferences and the Response to Incentives: Evidence from Personnel Data," The Quarterly Journal of Economics 120 (3), 917-962.

Bandiera O., I. Barankay I., and I. Rasul (2010). "Social incentives in the workplace,” Review of Economic Studies, 77(2), 417-458.

Barankay, I. (2012). "Rank Incentives. Evidence from a Randomized Workplace Experiment," Wharton School, University of Pennsylvania

Bohnet, I. and B.S. Frey (1999). "The sound of silence in prisoner's dilemma and dictator games," Journal of Economic Behavior \& Organization, 38, 43-57.

Buchan, N.R., Johnson, E.J., and Croson, R.T.A. (2006). "Let's get personal: an international examination of the influence of communication, culture and social distance on other regarding preferences," Journal of Economic Behavior \& Organization, 60, 373-398.

Charness, G., D. Masclet, and M.C. Villeval (2013). "The dark side of competition for status," Forthcoming in Management Science.

Eriksson, T., A. Poulsen, and M.C. Villeval (2009). "Feedback and Incentives: Experimental Evidence," Labour Economics 16 (6), 679-688.

Falk, A., and A. Ichino (2006). "Clean evidence on peer pressure," Journal of Labor Economics 24 (1), 39-57.

Fershtman C., and U. Gneezy (2011). "The trade-off between performance and quitting in highpower tournaments," forthcoming in the Journal of the European Economic Association.

Elsbach, K.D., Cable, D.M., and Sherman, J.W. (2010). "How passive 'face time' affects perceptions of employees: Evidence of spontaneous trait inference," Human Relations, 63(6) $735-760$.

Gill, D. and V. Prowse (2012). "A Structural Analysis of Disappointment Aversion in a Real Effort Competition," American Economic Review, 102(1), 469-503.

Greiner, B. (2015). "Subject pool recruitment procedures: organizing experiments with ORSEE,"Journal of the Economic Science Association, 1, 114-125.

Guryan J., K. Kroft, and M. Notowidigdo (2009).“ Peer effects in the workplace: Evidence from random groupings in professional golf tournaments," American Economic Journal: Applied Economics 1 (4), 34-68.

Ichino, A. and G. Maggi (2000). "Work environment and individual background: Explaining regional shirking differentials in large Italian firm," The Quarterly Journal of Economics 115 (3), 1057-1090.

Joyce, A (2002). "Early to arrive, early to exit. Less face time in the office can mean little recognition, fewer promotions," The Washington Post, 23 June, H06. 
Kandel, E. and E.P. Lazear (1992). "Peer Pressure and Partnerships," Journal of Political Economy 100 (4), 801-817.

Kossek, E.E. and Van Dyne, L. (2008). "Face-time matters: A cross-level model of how work-life flexibility influences work performance of individuals and groups," In Korabik K., Leor D., and Whitehead D. (eds), Handbook of Work-Family Integration: Research, Theory, and Best Practices. Amsterdam, Elsevier, 305-330.

Linardi, S. and M.A. McConnell (2011). "No excuses for good behavior: Volunteering and the social environment," Journal of Public Economics 95 (5-6), 445-445.

Manski, C.F. (1993). "Identification of Endogenous Social Effects: The Reflection Problem," Review of Economic Studies 60(3), 531-542.

Mas, A., and E. Moretti (2009). "Peers at work," American Economic Review 99 (1), 112-145.

Singer, J., and J. Willett, (1993). "It's about Time: Using Discrete-Time Survival Analysis to Study Duration and the Timing of Events," Journal of Educational Statistics, 18(2) 155-195.

Slonim, R., and E. Garbarino (2006). "Increases in trust and altruism from partner selection: experimental evidence," Experimental Economics 11(2), 134-153.

Stark, O., and J.E. Taylor (1991). "Migration Incentives, Migration Types: The Role of Relative Deprivation," The Economic Journal 101, 1163-1178.

Zeiliger R. (2000). "A Presentation of Regate, Internet Based Software or Experimental Economics," http://www.gate.cnrs.fr/ zeiliger/regate/RegateIntro.ppt., GATE, Lyon. 
Table 1: Summary of conjectures and their relationship to the experimental design

\begin{tabular}{lcccc}
\hline \hline & & \multicolumn{2}{c}{ Peer Treatments } \\
Conjectures & Single & NCNF & NCF & CF \\
\hline Peer Pressure and Social Comparisons on Quitting Times & - & Present & Present & Present \\
Peer Pressure and Social Comparisons on Performance & - & - & Present & Present \\
Sociability & - & - & - & Present \\
\hline \hline
\end{tabular}


Table 2. Summary statistics

\begin{tabular}{|c|c|c|c|c|}
\hline Treatment & Single & $N C N F$ & $N C F$ & $C F$ \\
\hline \multicolumn{5}{|c|}{ Mean score (correct entries) in the preliminary period (3 minutes) } \\
\hline All participants & $3.35(2.33)$ & $2.62(2.30)$ & $2.50(2.25)$ & $2.58(1.60)$ \\
\hline \multicolumn{5}{|c|}{ Mean score in the compulsory time (15 minutes) } \\
\hline All participants & $23.77(11.22)$ & $22.77(9.18)$ & $22.04(11.55)$ & $24.42(8.24)$ \\
\hline First quitters & $22.68(9.46)$ & $19.08(5.99)$ & $20.38(12.12)$ & $23.15(9.87)$ \\
\hline Second quitters & $24.77(12.19)$ & $26.46(10.50)$ & $23.69(11.18)$ & $25.69(6.37)$ \\
\hline \multicolumn{5}{|c|}{ Mean score over the total working time } \\
\hline All participants & $100.69(77.63)$ & $82.96(65.32)$ & $81.08(70.52)$ & $115.19(75.94)$ \\
\hline First quitters & $67.36(65.22)$ & $50.15(50.16)^{* *}$ & $55.77(64.19)^{* *}$ & $101.54(91.34)$ \\
\hline Second quitters & $131.56(72.57)$ & $115.77(63.56)$ & $106.38(69.67)$ & $128.85(57.15)$ \\
\hline \multicolumn{5}{|c|}{ Mean number of correct plus incorrect entries in the compulsory time (15 minutes) } \\
\hline All participants & $30.46(12.98)$ & $27.85(9.87)$ & $27.62(11.75)$ & $28.35(7.95)$ \\
\hline First quitters & $31.70(12.82)$ & $25.23(7.72)$ & $26.38(10.86)$ & $27.15(8.91)$ \\
\hline Second quitters & $29.32(12.56)$ & $30.46(11.34)$ & $28.85(12.90)$ & $29.54(7.01)$ \\
\hline \multicolumn{5}{|c|}{ Mean number of correct plus incorrect entries in the total working time } \\
\hline All participants & $121.04(81.88)$ & $97.31(72.60)$ & $98.35(80.80)$ & $131.81(81.19)$ \\
\hline First quitters & $85.10(67.68)$ & $60.38(52.78)^{* *}$ & $69.38(74.01)^{* *}$ & $117.92(97.62)$ \\
\hline Second quitters & $154.31(76.82)$ & $134.23(72.39)$ & $127.31(79.42)$ & $145.69(61.51)$ \\
\hline \multicolumn{5}{|c|}{ Mean score by minute in preliminary period ( 3 minutes) } \\
\hline All participants & $1.12(0.78)$ & $0.87(0.77)$ & $0.83(0.75)$ & $0.86(0.53)$ \\
\hline \multicolumn{5}{|c|}{ Mean score by minute in compulsory time (15 minutes) } \\
\hline All participants & $1.58(0.75)$ & $1.52(0.61)$ & $1.47(0.77)$ & $1.63(0.55)$ \\
\hline First quitters & $1.51(0.63)$ & $1.27(0.40)$ & $1.36(0.81)$ & $1.54(0.66)$ \\
\hline Second quitters & $1.65(0.81)$ & $1.76(0.70)$ & $1.58(0.75)$ & $1.71(0.42)$ \\
\hline \multicolumn{5}{|c|}{ Mean score by minute in total working time } \\
\hline All participants & $1.85(0.83)$ & $1.77(0.70)$ & $1.73(0.83)$ & $1.98(0.75)$ \\
\hline First quitters & $1.68(0.72)$ & $1.43(0.48)$ & $1.54(0.88)$ & $1.84(0.98)$ \\
\hline Second quitters & $2.01(0.86)$ & $2.12(0.72)$ & $1.92(0.77)$ & $2.11(0.42)^{* *}$ \\
\hline \multicolumn{5}{|c|}{ Mean number of entries by minute in compulsory time (15 minutes) } \\
\hline All participants & $2.03(0.87)$ & $1.86(0.66)$ & $1.84(0.78)$ & $1.89(0.53)$ \\
\hline First quitters & $2.11(0.85)$ & $1.68(0.51)$ & $1.76(0.72)$ & $1.81(0.59)$ \\
\hline Second quitters & $1.95(0.84)$ & $2.03(0.76)$ & $1.95(0.85)$ & $1.97(0.47)$ \\
\hline \multicolumn{5}{|c|}{ Mean number of entries by minute in total working time } \\
\hline All participants & $2.36(0.87)$ & $2.15(0.70)$ & $2.18(0.86)$ & $2.33(0.74)$ \\
\hline First quitters & $2.34(0.87)$ & $1.85(0.52)$ & $2.01(0.82)$ & $2.23(0.96)$ \\
\hline Second quitters & $2.39(0.87)$ & $2.45(0.75)$ & $2.35(0.88)$ & $2.43(0.46)$ \\
\hline
\end{tabular}


Mean quitting time (in minutes - compulsory time included)

$\begin{array}{lcccc}\text { All participants } & 50.12(24.67) & 42.33(25.71) & 41.27(25.65) & 52.79(23.58) \\ \text { First quitters } & 36.31(22.37) & 31.49(24.81)^{* *} & 29.85(24.84)^{* *} & 46.08(26.24) \\ \text { Second quitters } & 62.91(18.06) & 53.16(22.52) & 52.69(21.70) & 59.49(19.29) \\ & & & & \\ \text { Mean within-pair difference } & 26.59(21.59) & 21.67(22.29) & 22.85(21.88) & 13.41(20.36)^{* *} \\ & & & & \\ \text { \% quitting as soon as allowed } & 15.38 & 11.54 & 26.92 & 3.85 \\ \text { \% quitting at the end } & 3.85 & 11.54 * * & 7.69 & 11.54^{* *} \\ \text { \% quitting at the same time } & 20.41 & 23.08 & 23.08 & 53.85^{* * *}\end{array}$

Notes: The score is defined as the number of correct entries while the number of entries includes both correct and incorrect answers. In the Single treatment, we generated all $676(26 * 26)$ hypothetical pairs matching each participant with each of the other participants. In these hypothetical pairs, the worker who has the lowest quitting time is defined as the first quitter and the other worker as the second quitter. Quitting at the same time means that the two co-workers quit within a minute. $* * *, * *$, and * indicate significance at the $1 \%, 5 \%$ and $10 \%$ level, respectively, in two-tailed pairwise Mann-Whitney tests in which each pair (each worker in the Single treatment) gives one independent observation and where the Single treatment is taken as the reference category. 
Table 3. Determinants of productivity in the compulsory work time

\begin{tabular}{|c|c|c|c|c|c|c|c|}
\hline \multirow{2}{*}{$\begin{array}{l}\text { Dependent variable: } \\
\text { Score per minute in the } 15 \\
\text { minute compulsory } \\
\text { working time }\end{array}$} & \multicolumn{6}{|c|}{ OLS Estimates } & \multirow[b]{2}{*}{ (7) } \\
\hline & (1) & (2) & (3) & (4) & (5) & (6) & \\
\hline Single treatment & Ref. & Ref. & & Ref. & Ref. & - & - \\
\hline All peer treatments & $\begin{array}{c}0.105 \\
(0.129)\end{array}$ & - & - & $\begin{array}{c}0.077 \\
(0.217)\end{array}$ & - & - & - \\
\hline NCNF treatment & - & $\begin{array}{c}0.072 \\
(0.143)\end{array}$ & Ref. & - & $\begin{array}{c}0.189 \\
(0.264)\end{array}$ & Ref. & - \\
\hline NCF treatment & - & $\begin{array}{c}0.070 \\
(0.156)\end{array}$ & $\begin{array}{l}-0.015 \\
(0.134)\end{array}$ & - & $\begin{array}{l}-0.148 \\
(0.224)\end{array}$ & $\begin{array}{l}-0.357^{*} \\
(0.197)\end{array}$ & - \\
\hline CF treatment & - & $\begin{array}{c}0.176 \\
(0.158)\end{array}$ & $\begin{array}{c}0.112 \\
(0.136)\end{array}$ & - & $\begin{array}{c}0.254 \\
(0.250)\end{array}$ & $\begin{array}{c}0.099 \\
(0.213)\end{array}$ & - \\
\hline Ability & $\begin{array}{c}0.660 * * * \\
(0.088)\end{array}$ & $\begin{array}{c}0.657 * * * \\
(0.091)\end{array}$ & $\begin{array}{c}0.639 * * * \\
(0.114)\end{array}$ & $\begin{array}{c}0.641 * * * \\
(0.136)\end{array}$ & $\begin{array}{c}0.637 * * * \\
(0.140)\end{array}$ & $\begin{array}{c}0.473 * * \\
(0.221)\end{array}$ & $\begin{array}{c}0.469 * * \\
(0.190)\end{array}$ \\
\hline Ability * peer treatments & - & - & - & $\begin{array}{c}0.027 \\
(0.172)\end{array}$ & - & - & - \\
\hline Ability * NCNF treatment & - & - & - & - & $\begin{array}{l}-0.139 \\
(0.260)\end{array}$ & - & - \\
\hline Ability * NCF treatment & - & - & - & - & $\begin{array}{c}0.254 \\
(0.167)\end{array}$ & $\begin{array}{l}0.400 * \\
(0.237)\end{array}$ & - \\
\hline Ability * CF treatment & - & - & - & & $\begin{array}{l}-0.093 \\
(0.199)\end{array}$ & $\begin{array}{c}0.015 \\
(0.260)\end{array}$ & - \\
\hline $\begin{array}{l}\text { Task-related } \\
\text { communication }\end{array}$ & - & - & - & - & - & - & $\begin{array}{l}0.268^{*} \\
(0.143)\end{array}$ \\
\hline $\begin{array}{l}\text { Task unrelated } \\
\text { communication }\end{array}$ & - & - & - & - & - & - & $\begin{array}{c}-0.481^{* *} \\
(0.162)\end{array}$ \\
\hline Male & $\begin{array}{c}-0.201 * * \\
(0.096)\end{array}$ & $\begin{array}{c}-0.190 * * \\
(0.094)\end{array}$ & $\begin{array}{l}-0.083 \\
(0.080)\end{array}$ & $\begin{array}{c}-0.202 * * \\
(0.096)\end{array}$ & $\begin{array}{l}-0.173^{*} \\
(0.101)\end{array}$ & $\begin{array}{l}-0.055 \\
(0.088)\end{array}$ & $\begin{array}{l}-0.182 \\
(0.147)\end{array}$ \\
\hline Constant & $\begin{array}{c}0.980 * * * \\
(0.161)\end{array}$ & $\begin{array}{c}0.976^{* * *} * \\
(0.163)\end{array}$ & $\begin{array}{c}1.006 * * * \\
(0.107)\end{array}$ & $\begin{array}{c}1.001 * * * \\
(0.206)\end{array}$ & $\begin{array}{c}0.987 * * * \\
(0.212)\end{array}$ & $\begin{array}{c}1.136 * * * \\
(0.166)\end{array}$ & $\begin{array}{c}1.408^{* * *} * \\
(0.194)\end{array}$ \\
\hline $\mathrm{N}$ & 104 & 104 & 78 & 104 & 104 & 78 & 26 \\
\hline $\mathrm{R}^{2}$ & 0.442 & 0.446 & 0.443 & 0.442 & 0.473 & 0.484 & 0.296 \\
\hline
\end{tabular}

Notes: All models are OLS regressions. Robust standard errors clustered at the pair level are in parentheses. Ability is the score per minute during the three-minute initial part. Columns (3) and (6) exclude data from the Single treatment. Column (7) only includes the data from the CF treatment.*** means significant at the 0.01 level, ** at the 0.05 level, and * at the 0.10 level. 
Table 4. Determinants of quitting time - Heckman two-step regressions

\begin{tabular}{|c|c|c|c|c|c|c|}
\hline \multirow[t]{2}{*}{$\begin{array}{l}\text { Dependent } \\
\text { variable }\end{array}$} & \multirow{2}{*}{$\begin{array}{c}\text { Probit } \\
\text { Decision to } \\
\text { keep working } \\
\text { at the end of } \\
\text { compulsory } \\
\text { time (1) }\end{array}$} & \multicolumn{5}{|c|}{$\begin{array}{l}\text { OLS } \\
\text { Quitting time conditional on decision to keep working }\end{array}$} \\
\hline & & $\begin{array}{c}\text { All } \\
\text { subjects } \\
(2)\end{array}$ & $\begin{array}{l}\text { First } \\
\text { quitters } \\
\text { (3) }\end{array}$ & $\begin{array}{l}\text { Second } \\
\text { quitters } \\
\text { (4) }\end{array}$ & $\begin{array}{c}\text { First } \\
\text { quitters } \\
\text { (5) }\end{array}$ & $\begin{array}{l}\text { Second } \\
\text { quitters } \\
\text { (6) }\end{array}$ \\
\hline $\begin{array}{l}\text { Single } \\
\text { treatment }\end{array}$ & Ref. & Ref. & Ref. & Ref. & - & - \\
\hline $\begin{array}{l}\text { NCNF } \\
\text { treatment }\end{array}$ & $\begin{array}{c}0.056 \\
(0.065)\end{array}$ & $\begin{array}{r}-10.494 \\
(7.591)\end{array}$ & $\begin{array}{l}-11.636 \\
(8.686)\end{array}$ & $\begin{array}{l}-10.927 \\
(6.847)\end{array}$ & Ref. & Ref. \\
\hline $\begin{array}{l}\text { NCF } \\
\text { treatment }\end{array}$ & $\begin{array}{l}-0.050 \\
(0.082)\end{array}$ & $\begin{array}{l}-5.603 \\
(8.842)\end{array}$ & $\begin{array}{l}14.412 \\
(21.647)\end{array}$ & $\begin{array}{l}-4.074 \\
(12.490)\end{array}$ & $\begin{array}{c}4.351 \\
(17.651)\end{array}$ & $\begin{array}{l}-2.271 \\
(11.539)\end{array}$ \\
\hline $\begin{array}{l}\mathrm{CF} \\
\text { treatment }\end{array}$ & $\begin{array}{l}0.120^{* *} \\
(0.058)\end{array}$ & $\begin{array}{l}-1.952 \\
(7.841)\end{array}$ & $\begin{array}{c}-1.926 \\
(12.762)\end{array}$ & $\begin{array}{l}-6.835 \\
(6.458)\end{array}$ & $\begin{array}{l}19.021 \\
(11.217)\end{array}$ & $\begin{array}{l}7.603 \\
(9.057)\end{array}$ \\
\hline Ability & $\begin{array}{l}0.111 * * \\
(0.047)\end{array}$ & - & - & - & - & - \\
\hline Male & $\begin{array}{l}-0.070 \\
(0.056)\end{array}$ & $\begin{array}{r}-5.3131 \\
(4.840)\end{array}$ & $\begin{array}{c}1.856 \\
(29.864)\end{array}$ & $\begin{array}{l}13.330 \\
(14.226)\end{array}$ & $\begin{array}{c}-16.355^{*} \\
(9.403)\end{array}$ & $\begin{array}{c}1.316 \\
(7.738)\end{array}$ \\
\hline IMR & - & $\begin{array}{c}4.382 \\
(20.391)\end{array}$ & $\begin{array}{l}-47.289 \\
(81.670)\end{array}$ & $\begin{array}{l}-35.096 \\
(42.632)\end{array}$ & $\begin{array}{c}37.261 \\
(51.812)\end{array}$ & $\begin{array}{c}8.901 \\
(34.243)\end{array}$ \\
\hline Constant & - & $\begin{array}{c}58.5101 * * * \\
(6.975)\end{array}$ & $\begin{array}{c}55.614 * * * \\
(7.438)\end{array}$ & $\begin{array}{c}64.696 * * * \\
(4.248)\end{array}$ & $\begin{array}{c}36.599 * * * \\
(12.131)\end{array}$ & $\begin{array}{c}50.596^{* * *} * \\
(8.892)\end{array}$ \\
\hline $\mathrm{N}$ & 104 & 89 & 259 & 380 & 28 & 39 \\
\hline $\log \mathrm{L}$ & -37.248 & - & - & - & - & - \\
\hline Pseudo/R ${ }^{2}$ & 0.132 & 0.043 & 0.128 & 0.044 & 0.165 & 0.027 \\
\hline
\end{tabular}

Notes: Robust standard errors (in parentheses) are clustered at the pair level, except for the Single treatment in columns (3) and (4) where they are clustered at the individual level since a subject cannot have influenced another pair member but each individual is observed in several hypothetical pairs. Column (1) report the marginal effects of estimates of a probit model of the decision to keep working at the end of the compulsory period. The other columns report the estimates for all treatments of OLS models conditional on the decision to keep working after the compulsory working time. In Columns (3) and (4), we include the data from hypothetical pairs in the Single treatment. Columns (5) and (6) exclude data from the Single treatment and report only the estimates of the conditional OLS equation including the Inverse of the Mill's ratio (IMR) obtained from an equation selection not reported here but available upon request. Ability is the score per minute in the initial part. $* * *$ means significant at the 0.01 level, ** at the 0.05 level, and * at the 0.10 level. 
Table 5: Determinants of Workers Continuing to Work Probit (non-parametric hazard) estimates

\begin{tabular}{|c|c|c|c|c|}
\hline Treatments & $\begin{array}{c}\text { Single } \\
\text { and NCNF } \\
(1)\end{array}$ & $\begin{array}{c}\text { Single } \\
\text { and NCF } \\
(2)\end{array}$ & $\begin{array}{l}\text { Single } \\
\text { and CF } \\
(3)\end{array}$ & $\begin{array}{l}\text { All } \\
\text { (4) }\end{array}$ \\
\hline Constant & $\begin{array}{l}0.847^{*} \\
(0.464)\end{array}$ & $\begin{array}{l}0.834^{*} \\
(0.465)\end{array}$ & $\begin{array}{c}1.299 * * * \\
(0.485)\end{array}$ & $\begin{array}{c}0.960 * * * \\
(0.349)\end{array}$ \\
\hline Minute & $\begin{array}{c}0.065^{* * *} \\
(0.025)\end{array}$ & $\begin{array}{c}0.058 * * \\
(0.025)\end{array}$ & $\begin{array}{c}0.031 \\
(0.026)\end{array}$ & $\begin{array}{c}0.053 * * * \\
(0.019)\end{array}$ \\
\hline $\begin{array}{l}\text { Minute-Squared } \\
(=\text { est. times 100) }\end{array}$ & $\begin{array}{c}-0.069 * * \\
(0.030)\end{array}$ & $\begin{array}{c}-0.060 * * \\
(0.030)\end{array}$ & $\begin{array}{l}-0.025 \\
(0.031)\end{array}$ & $\begin{array}{c}-0.050 * * \\
(0.023)\end{array}$ \\
\hline Ability & $\begin{array}{l}0.006 \\
(0.30)\end{array}$ & $\begin{array}{c}0.044 \\
(0.036)\end{array}$ & $\begin{array}{c}0.039 \\
(0.033)\end{array}$ & $\begin{array}{c}0.020 \\
(0.024)\end{array}$ \\
\hline $\begin{array}{l}\text { Partner Working } \\
\text { * NCNF }\end{array}$ & $\begin{array}{l}-0.024 \\
(0.201)\end{array}$ & & & \\
\hline $\begin{array}{l}\text { Partner Not Working } \\
\text { * NCNF }\end{array}$ & $\begin{array}{l}-0.305^{*} \\
(0.184)\end{array}$ & & & \\
\hline $\begin{array}{l}\text { Partner Working } \\
* \mathrm{NCF}\end{array}$ & & $\begin{array}{l}-0.030 \\
(0.206)\end{array}$ & & \\
\hline $\begin{array}{l}\text { Partner Not Working } \\
\text { * NCF }\end{array}$ & & $\begin{array}{l}-0.256 \\
(0.208)\end{array}$ & & \\
\hline $\begin{array}{l}\text { Partner Working } \\
* \mathrm{NCNF}+\mathrm{NCF}\end{array}$ & & & & $\begin{array}{l}-0.030 \\
(0.157)\end{array}$ \\
\hline $\begin{array}{l}\text { Partner Not Working } \\
* \mathrm{NCNF}+\mathrm{NCF}\end{array}$ & & & & $\begin{array}{l}-0.272 * \\
(0.152)\end{array}$ \\
\hline $\begin{array}{l}\text { Partner Working } \\
\text { * CF }\end{array}$ & & & $\begin{array}{l}0.425 * * \\
(0.192)\end{array}$ & $\begin{array}{c}0.425 * * \\
(0.200)\end{array}$ \\
\hline $\begin{array}{l}\text { Partner Not Working } \\
* \mathrm{CF}\end{array}$ & & & $\begin{array}{l}-0.437 \\
(0.287)\end{array}$ & $\begin{array}{l}-0.486^{*} \\
(0.288)\end{array}$ \\
\hline $\begin{array}{l}\text { p-value for Test: } \\
\text { Partner Working = } \\
\text { Partner NOT } \\
\text { working }\end{array}$ & $\begin{array}{c}\mathrm{chi}^{2}=1.44 \\
p=0.23\end{array}$ & $\begin{array}{c}\mathrm{chi}^{2}=0.69 \\
p=0.41\end{array}$ & $\begin{array}{c}\mathrm{chi}^{2}=5.08 \\
p=0.024\end{array}$ & \\
\hline $\begin{array}{l}\mathrm{N} \\
\text { Log-likelihood }\end{array}$ & $\begin{array}{c}1702 \\
-156.79 \\
\end{array}$ & $\begin{array}{c}1677 \\
-155.76 \\
\end{array}$ & $\begin{array}{c}1955 \\
-133.62 \\
\end{array}$ & $\begin{array}{c}3440 \\
-295.82 \\
\end{array}$ \\
\hline
\end{tabular}

Notes: Robust standard errors are clustered at the pair level. Minute and Minute ${ }^{2}$ are the times during the optional work period (minutes 15 to 75). Partner Working * Treatment X equals 1 if a subject was in treatment $X$ and his peer in Treatment $X$ was working at time $t-1$, and equals 0 otherwise. Partner Not Working * Treatment $\mathrm{X}$ equals 0 if a subject was in treatment $\mathrm{X}$ and his peer in Treatment $\mathrm{X}$ was not working at time $\mathrm{t}-1$, and equals 0 otherwise. ${ }^{* * *}$ means significant at the 0.01 level, ${ }^{* *}$ at the 0.05 level, $*$ at the 0.10 level. 


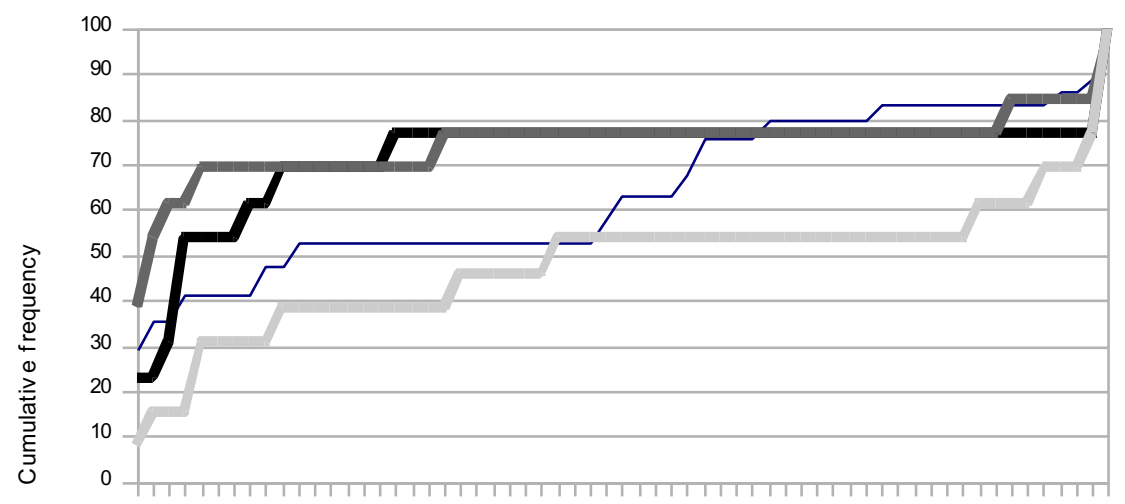

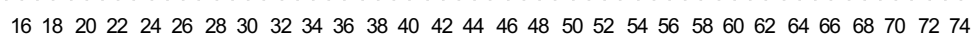

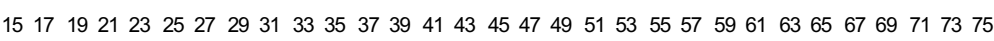

Quitting time

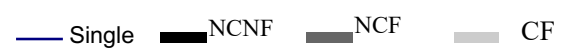

Figure 1a.

frequency of quitting time of the first quitter, by treatment

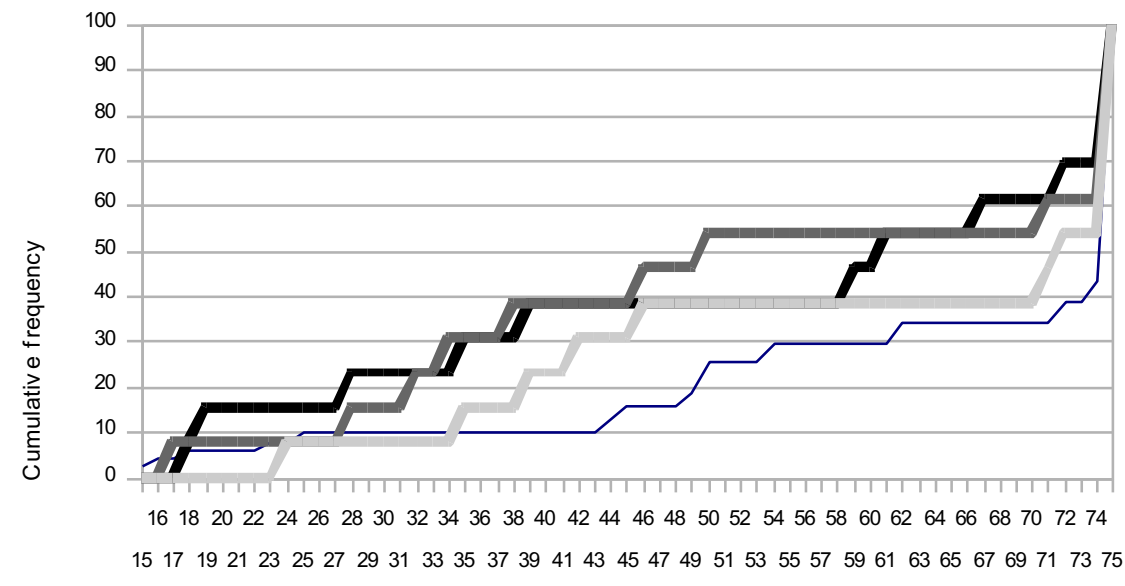

Quitting time

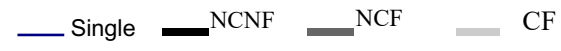

Figure 1b. Cumulative frequency of quitting time of the second quitter, by treatment 


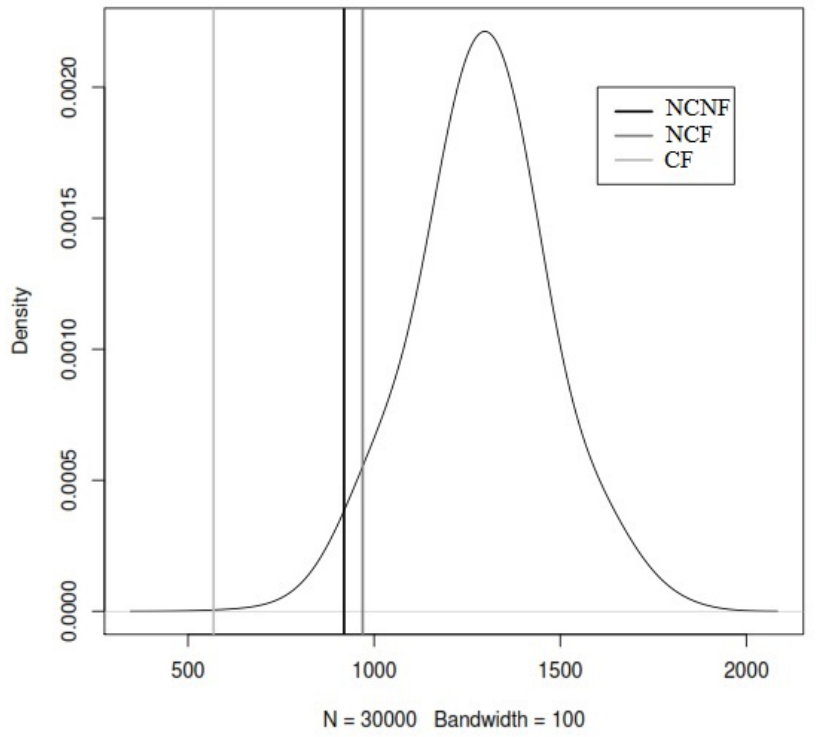

Fig. 2a. Within-pair S.D. in quitting time

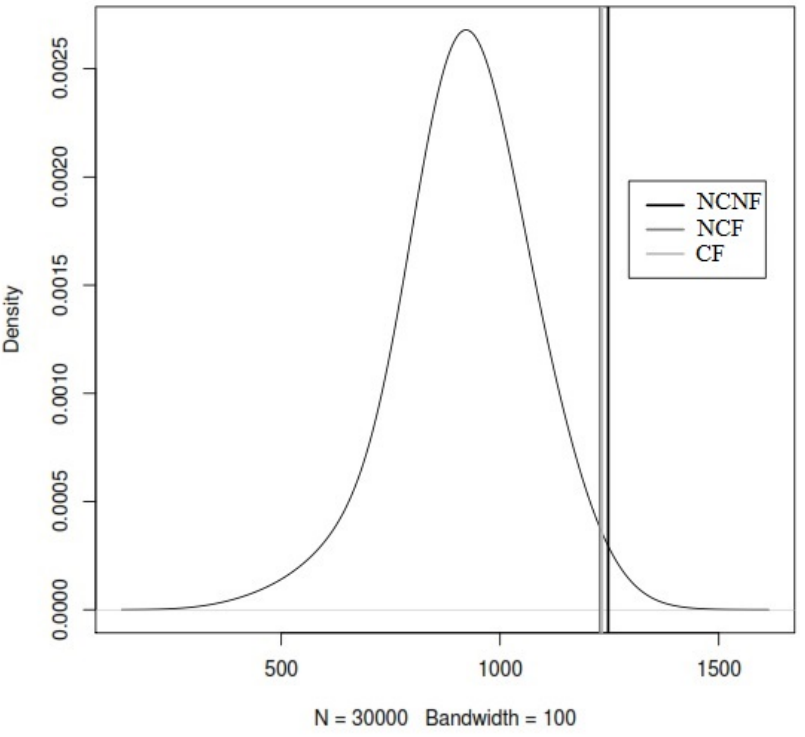

Fig. 2b. Between-pair S.D. in quitting time between true pairs in the peer treatments and the hypothetical pairs in the Single treatment

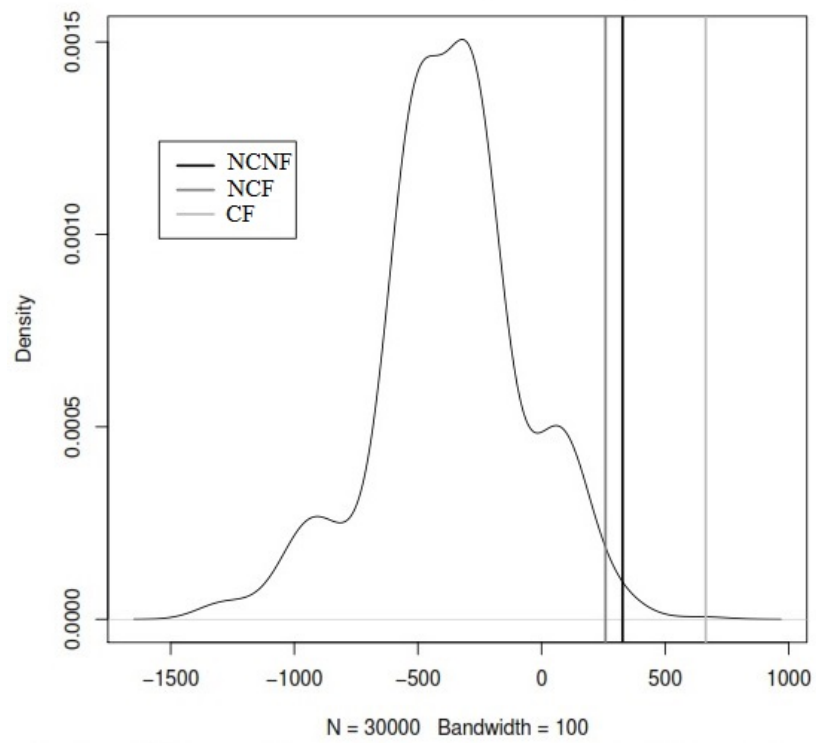

Fig. 2c. Difference between the between-pair SD and the within-pair SD in each peer treatment with the difference computed for the hypothetical pairs in the Single treatment 


\title{
Quitting and Peer Effects at Work
}

\author{
Julie ROSAZ, Robert SLONIM, Marie Claire VILLEVAL
}

\section{Supplementary materials}

Appendix A. The experimental room

Appendix B. Instructions

Appendix C. Distribution of the reasons given by the subjects to explain their quitting time Appendix D. Supplementary regressions models

Appendix E. Procedure for comparing the within-pair and between-pair differences in the quitting time between the single and the peer treatments

Appendix F. Kaplan-Meier survival estimates of the quitting time, by treatment

Appendix G. Determinants of workers continuing to work 


\section{APPENDIX A. THE EXPERIMENTAL ROOM}

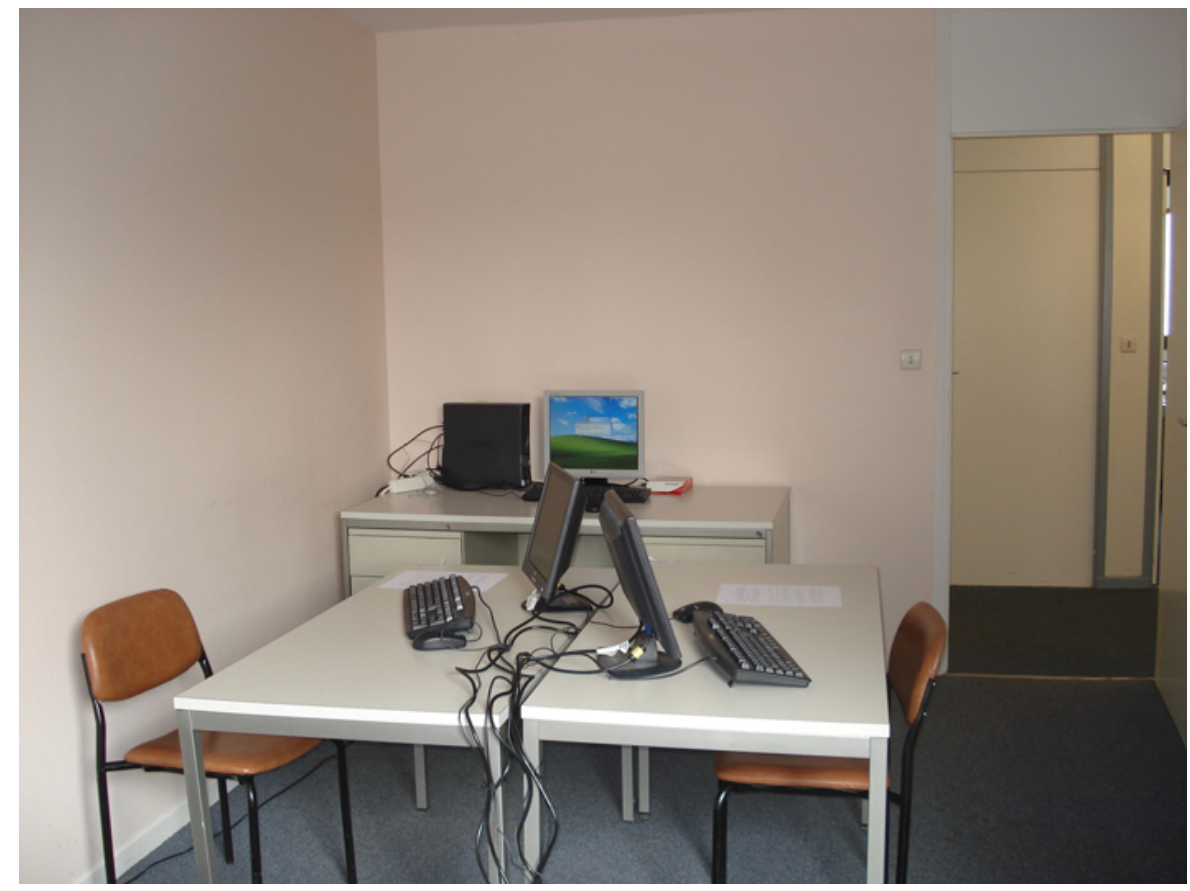

Picture 1. The desks in the Single treatment and in the peer treatments with communication (CF treatment)

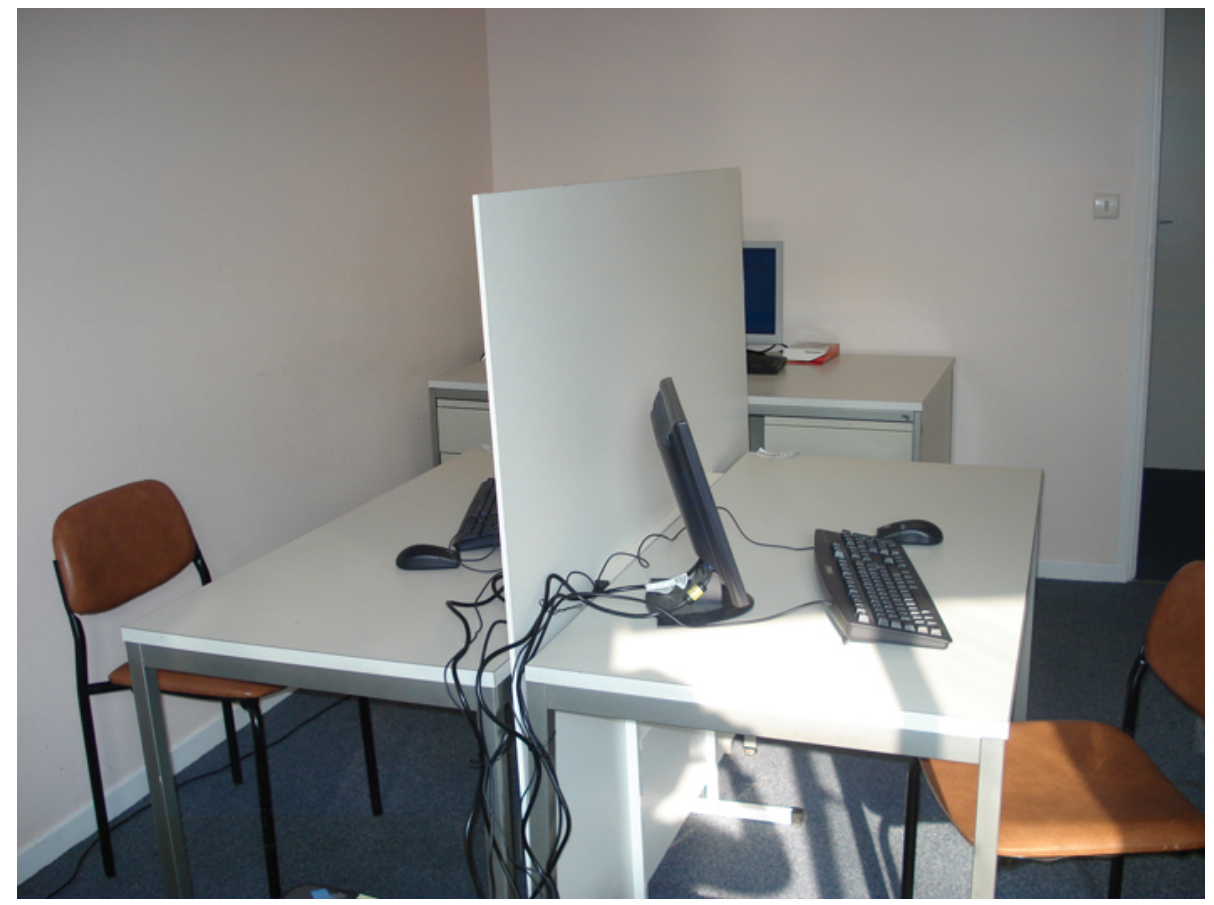

Picture 2. The desks in the peer treatments with no communication (NCNF and NCF treatments) 


\section{APPENDIX B. INSTRUCTIONS}

The original of these instructions were written in French. In the instructions of each pair treatment, we put in italics the paragraphs that differ from the instructions of the Single treatment. In the original instructions, italics were not used.

\section{Appendix B1. Instructions for the Single treatment}

You are about to participate in an experiment during which you can earn money. Just imagine that you were hired for a temporary job. The job consists in performing a task. You will be paid for each unit of output produced as explained below. Your earnings during this experiment are expressed in points, with:

$$
30 \text { points }=1 \text { Euro }
$$

\section{Description of the task}

The task consists of adding up numbers and multiplying the result by three to produce units of output. Precisely, you have to add up four two-digit numbers that are randomly generated and to multiply the result by three, like in the following example:

$\begin{array}{ll}\text { Example: } & 12 \\ & 53 \\ & 66 \\ & 24\end{array}$

You have to add up these numbers, that is $12+53+66+24$, and multiply the result by three. In this example, you produce one unit of output if your answer is 465 , and you do not produce any unit if your answer is different.

You must make these calculations in your head. The use of paper, pencil, or calculator is forbidden.

Then, you enter your answer in your computer and you validate it. You are immediately informed on whether your answer is correct or not. If your answer is correct, your score increases by one unit. If your answer is wrong, your score does not change. Whatever your answer is correct or wrong, a new series of numbers appears automatically on your screen.

\section{Determination of payoffs}

You are paid 300 points for this task regardless of your score. In addition, you earn 1 point for each unit produced (i.e. for each correct answer). You do not lose any point if you submit a wrong answer.

\section{Timing}

We ask you to perform the task during a minimum of 15 minutes. However, you can work longer. Beyond the first 15 minutes, you have to decide when to stop the task. However, you cannot work longer than 75 minutes.

When you decide to stop, press the « stop » button on your screen. You will be asked to confirm or not you choice. If you confirm this choice, it is definitive.

Once you have validated your decision to stop, the amount of your payoff is automatically transferred to the person in charge of the payments. You can leave the room and proceed directly to the payment room to fill out a postexperimental questionnaire, to get paid, and to pick up your belongings. The person in charge of the payment is not aware of the content of the experiment.

\section{Information on your screen}

On your screen, you are continuously informed on the time elapsed from the beginning of the task, on your current output (i.e. the current number of correct answers), and on your current total earnings.

Moreover, your score is represented graphically by means of a cursor that lengthens as soon as you have submitted a new set of five correct answers (one bar = five correct answers), as indicated in the following screenshot. 
OK

Now, you can perform the task.

Your output is the total number of correct answers.

One green bar means five correct answers.

Time elapsed: 32 minutes and 24 seconds

Your output is: $\quad 16$ points ||

Then you earnings are: $\quad 10.53$ euros

The numbers to add up are: $\mathbf{1 5}$

18

26

75

Multiply this sum by three end enter your answer:

You want to stop: $\square$ (then press the validating button)

Validate

\section{Preliminary task}

Before starting, you are required to add up series of four two-digit numbers and multiply the result by three as fast as you can during three minutes. You will be paid 10 points for each correct answer submitted during these three minutes with one chance out of two, and you will be paid 0 point with one chance out of two.

At the end of the experiment, in the payment room, you will toss a coin. If you toss tail, you will be paid 10 points for each correct answer submitted during this preliminary task, in addition to your other earnings. If you toss head you earn nothing in addition to your other earnings.

If you have any question regarding these instructions, please ask them now. After the preliminary task, the experimentalist will leave the room definitively. 


\section{Appendix B2. Instructions for the NCNF treatment}

You and another participant are about to participate in an experiment during which you can earn money. Just imagine that you were hired for a temporary job. The job consists in performing a task. You will be paid for each unit of output produced as explained below. Your earnings during this experiment are expressed in points, with:

$$
30 \text { points }=1 \text { Euro }
$$

\section{Description of the task}

The task consists of adding up numbers and multiplying the result by three to produce units of output. Precisely, you have to add up four two-digit numbers that are randomly generated and to multiply the result by three, like in the following example:

Example: $\quad 12$

66

24

You have to add up these numbers, that is $12+53+66+24$, and multiply the result by three. In this example, you produce one unit of output if your answer is 465 , and you do not produce any unit if your answer is different.

You must make these calculations in your head. The use of paper, pencil, or calculator is forbidden.

Then, you enter your answer in your computer and you validate it. You are immediately informed on whether your answer is correct or not. If your answer is correct, your score increases by one unit. If your answer is wrong, your score does not change. Whatever your answer is correct or wrong, a new series of numbers appears automatically on your screen.

\section{Determination of payoffs}

You are paid 300 points for this task regardless of your score. In addition, you earn 1 point for each unit produced (i.e. for each correct answer). You do not lose any point if you submit a wrong answer. The other participant's score does not account for your earnings.

\section{Timing}

We ask you to perform the task during a minimum of 15 minutes. However, you can work longer. Beyond the first 15 minutes, you have to decide when to stop the task. However, you cannot work longer than 75 minutes.

When you decide to stop, press the « stop » button on your screen. You will be asked to confirm or not you choice. If you confirm this choice, it is definitive.

Once you have validated your decision to stop, the amount of your payoff is automatically transferred to the person in charge of the payments. You can leave the room and proceed directly to the payment room to fill out a postexperimental questionnaire, to get paid, and to pick up your belongings. The person in charge of the payment is not aware of the content of the experiment.

\section{Information on your screen}

On your screen, you are continuously informed on the time elapsed from the beginning of the task, on your current output (i.e. the current number of correct answers), and on your current total earnings.

Moreover, your score is represented graphically by means of a cursor that lengthens as soon as you have submitted a new set of five correct answers (one bar = five correct answers), as indicated in the following screenshot. 
OK

Now, you can perform the task.

Your output is the total number of correct answers.

One green bar means five correct answers.

Time elapsed: 32 minutes and 24 seconds

\begin{tabular}{ll}
\hline Your output is: & 16 points || $\mid$ \\
Then you earnings are: & 10.53 euros
\end{tabular}

The numbers to add up are: $\mathbf{1 5}$

18

26

75

Multiply this sum by three end enter your answer:

You want to stop: $\square$ (then press the validating button)

Validate

\section{Preliminary task}

Before starting, you are required to add up series of four two-digit numbers and multiply the result by three as fast as you can during three minutes. You will be paid 10 points for each correct answer submitted during these three minutes with one chance out of two, and you will be paid 0 point with one chance out of two.

At the end of the experiment, in the payment room, you will toss a coin. If you toss tail, you will be paid 10 points for each correct answer submitted during this preliminary task, in addition to your other earnings. If you toss head you earn nothing in addition to your other earnings.

No participant is informed on the other participant's score.

\section{Communication}

Throughout the session it is strictly forbidden to speak or to exchange signs with the other participant, otherwise you might be excluded from the session and from any payment. Indeed, a microphone is located next to you and is connected with the experimentalist.

When you decide to stop the task and to quit the room, the same rules apply: do not talk to the other participant. Please leave room without speaking and proceed directly to the payment room.

If you have any question regarding these instructions, please ask them now. After the preliminary task, the experimentalist will leave the room definitively. 


\section{Appendix B3. Instructions for the NCF treatment}

You and another participant are about to participate in an experiment during which you can earn money. Just imagine that you were hired for a temporary job. The job consists in performing a task. You will be paid for each unit of output produced as explained below. Your earnings during this experiment are expressed in points, with:

$$
30 \text { points }=1 \text { Euro }
$$

\section{Description of the task}

The task consists of adding up numbers and multiplying the result by three to produce units of output. Precisely, you have to add up four two-digit numbers that are randomly generated and to multiply the result by three, like in the following example:

$\begin{array}{ll}\text { Example: } & 12 \\ & 53 \\ & 66 \\ & 24\end{array}$

You have to add up these numbers, that is $12+53+66+24$, and multiply the result by three. In this example, you produce one unit of output if your answer is 465 , and you do not produce any unit if your answer is different.

You must make these calculations in your head. The use of paper, pencil, or calculator is forbidden.

Then, you enter your answer in your computer and you validate it. You are immediately informed on whether your answer is correct or not. If your answer is correct, your score increases by one unit. If your answer is wrong, your score does not change. Whatever your answer is correct or wrong, a new series of numbers appears automatically on your screen.

\section{Determination of payoffs}

You are paid 300 points for this task regardless of your score. In addition, you earn 1 point for each unit produced (i.e. for each correct answer). You do not lose any point if you submit a wrong answer. The other participant's score does not account for your earnings.

\section{Timing}

We ask you to perform the task during a minimum of 15 minutes. However, you can work longer. Beyond the first 15 minutes, you have to decide when to stop the task. However, you cannot work longer than 75 minutes.

When you decide to stop, press the « stop » button on your screen. You will be asked to confirm or not you choice. If you confirm this choice, it is definitive.

Once you have validated your decision to stop, the amount of your payoff is automatically transferred to the person in charge of the payments. You can leave the room and proceed directly to the payment room to fill out a postexperimental questionnaire, to get paid, and to pick up your belongings. The person in charge of the payment is not aware of the content of the experiment.

\section{Information on your screen}

On your screen, you are continuously informed on the time elapsed from the beginning of the task, on your current output (i.e. the current number of correct answers), and on your current total earnings.

Moreover, your score is represented graphically by means of a cursor that lengthens as soon as you have submitted a new set of five correct answers (one bar = five correct answers), as indicated in the following screenshot.

You are also informed of the current score of the other participant (his current number of correct answers) and a cursor lengthens as soon as he has submitted a new set of five correct answers. 
OK

Now, you can perform the task.

Your output is the total number of correct answers.

One green bar means five correct answers.

Time elapsed: 32 minutes and 24 seconds

$\begin{array}{ll}\text { Your output is: } & 16 \text { points } \| \\ \text { Then you earnings are: } & 10.53 \text { euros } \\ \text { Your partner's output is: } & 11 \text { points } \|\end{array}$

The numbers to add up are: $\mathbf{1 5}$

\section{8 \\ 26 \\ 75}

Multiply this sum by three end enter your answer:

You want to stop: $\square$ (then press the validating button)

\section{Preliminary task}

Before starting, you are required to add up series of four two-digit numbers and multiply the result by three as fast as you can during three minutes. You will be paid 10 points for each correct answer submitted during these three minutes with one chance out of two, and you will be paid 0 point with one chance out of two.

At the end of the experiment, in the payment room, you will toss a coin. If you toss tail, you will be paid 10 points for each correct answer submitted during this preliminary task, in addition to your other earnings. If you toss head you earn nothing in addition to your other earnings.

No participant is informed on the other participant's score during the preliminary task.

\section{Communication}

Throughout the session it is strictly forbidden to speak or to exchange signs with the other participant, otherwise you might be excluded from the session and from any payment. Indeed, a microphone is located next to you and is connected with the experimentalist.

When you decide to stop the task and to quit the room, the same rules apply: do not talk to the other participant. Please leave room without speaking and proceed directly to the payment room.

If you have any question regarding these instructions, please ask them now. After the preliminary task, the experimentalist will leave the room definitively. 


\section{Appendix B4. Instructions for the CF treatment}

You and another participant are about to participate in an experiment during which you can earn money. Just imagine that you were hired for a temporary job. The job consists in performing a task. You will be paid for each unit of output produced as explained below. Your earnings during this experiment are expressed in points, with:

$$
30 \text { points }=1 \text { Euro }
$$

\section{Description of the task}

The task consists of adding up numbers and multiplying the result by three to produce units of output. Precisely, you have to add up four two-digit numbers that are randomly generated and to multiply the result by three, like in the following example:

$\begin{array}{ll}\text { Example: } & 12 \\ & 53 \\ & 66 \\ & 24\end{array}$

You have to add up these numbers, that is $12+53+66+24$, and multiply the result by three. In this example, you produce one unit of output if your answer is 465, and you do not produce any unit if your answer is different.

You must make these calculations in your head. The use of paper, pencil, or calculator is forbidden.

Then, you enter your answer in your computer and you validate it. You are immediately informed on whether your answer is correct or not. If your answer is correct, your score increases by one unit. If your answer is wrong, your score does not change. Whatever your answer is correct or wrong, a new series of numbers appears automatically on your screen.

\section{Determination of payoffs}

You are paid 300 points for this task regardless of your score. In addition, you earn 1 point for each unit produced (i.e. for each correct answer). You do not lose any point if you submit a wrong answer. The other participant's score does not account for your earnings.

\section{Timing}

We ask you to perform the task during a minimum of 15 minutes. However, you can work longer. Beyond the first 15 minutes, you have to decide when to stop the task. However, you cannot work longer than 75 minutes.

When you decide to stop, press the « stop » button on your screen. You will be asked to confirm or not you choice. If you confirm this choice, it is definitive.

Once you have validated your decision to stop, the amount of your payoff is automatically transferred to the person in charge of the payments. You can leave the room and proceed directly to the payment room to fill out a postexperimental questionnaire, to get paid, and to pick up your belongings. The person in charge of the payment is not aware of the content of the experiment.

\section{Information on your screen}

On your screen, you are continuously informed on the time elapsed from the beginning of the task, on your current output (i.e. the current number of correct answers), and on your current total earnings.

Moreover, your score is represented graphically by means of a cursor that lengthens as soon as you have submitted a new set of five correct answers (one bar = five correct answers), as indicated in the following screenshot.

You are also informed of the current score of the other participant (his current number of correct answers) and a cursor lengthens as soon as he has submitted a new set of five correct answers. 
OK

Now, you can perform the task.

Your output is the total number of correct answers.

One green bar means five correct answers.

Time elapsed: 32 minutes and 24 seconds

$\begin{array}{ll}\text { Your output is: } & 16 \text { points } \| \\ \text { Then you earnings are: } & 10.53 \text { euros } \\ \text { Your partner's output is: } & 11 \text { points } \|\end{array}$

The numbers to add up are: $\mathbf{1 5}$

\section{8 \\ 26 \\ 75}

Multiply this sum by three end enter your answer:

You want to stop: $\square$ (then press the validating button)

\section{Preliminary task}

Before starting, you are required to add up series of four two-digit numbers and multiply the result by three as fast as you can during three minutes. You will be paid 10 points for each correct answer submitted during these three minutes with one chance out of two, and you will be paid 0 point with one chance out of two.

At the end of the experiment, in the payment room, you will toss a coin. If you toss tail, you will be paid 10 points for each correct answer submitted during this preliminary task, in addition to your other earnings. If you toss head you earn nothing in addition to your other earnings.

No participant is informed on the other participant's score during the preliminary task.

\section{Communication}

Throughout the session you are allowed to communicate with the other participant as much as you like. The communication is recorded but is not listened to directly. The recording will not allow anyone to identify you.

If you have any question regarding these instructions, please ask them now. After the preliminary task, the experimentalist will leave the room definitively. 


\section{APPENDIX C. DISTRIBUTION OF THE REASONS GIVEN BY THE SUBJECTS TO EXPLAIN THEIR QUITTING TIME}

If subjects quit before the maximum duration, we then asked them to indicate, from a list of 11 possible reasons, which one explains the reason for quitting early.

If we exclude "other reasons," we can group the remaining reasons into four main categories:

- Insufficient incentives: gains were too small for the time spent

- Income-targeting: the subject earned what he expected or he earned enough money for today

- Task-related reasons: the subject didn't like the problems, the task was too boring

- Ability-related reasons: the subject was tired, it took too long to solve a problem, or the subject started to make too many mistakes.

The distribution of reasons across treatments is the following:

\begin{tabular}{|l|c|c|c|c|}
\hline Treatment & Single & $N C N F$ & $N C F$ & $C F$ \\
\hline Insufficient incentives & $9(42.84 \%)$ & $13(61.90 \%)$ & $13(68.42 \%)$ & $8(42.11 \%)$ \\
Income-targeting & $3(14.29 \%)$ & $2(9.52 \%)$ & $1(5.26 \%)$ & $1(5.26 \%)$ \\
Task-related reasons & $3(14.29 \%)$ & $1(4.76 \%)$ & $1(5.26 \%)$ & $1(5.26 \%)$ \\
Ability-related reasons & $3(14.29 \%)$ & $2(9.52 \%)$ & $3(15.80 \%)$ & $4(21.05 \%)$ \\
Others & $3(14.29 \%)$ & $3(14.30 \%)$ & $1(5.26 \%)$ & $5(26.32 \%)$ \\
\hline Total & $21(100 \%)$ & $21(100 \%)$ & $19(100 \%)$ & $19(100 \%)$ \\
\hline
\end{tabular}

Pairwise t-tests indicate that the only significant differences are found when we compare the importance of "insufficient incentives" in the peer treatments without communication (pooled together) with the Single treatment $(p=0.099)$ or with the CF treatment $(p=0.099)$. 


\section{APPENDIX D. SUPPLEMENTARY REGRESSIONS}

Table D1. Determinants of productivity in the compulsory work time, excluding the ability variable

\begin{tabular}{|c|c|c|c|}
\hline \multirow{2}{*}{$\begin{array}{l}\text { Dependent variable: } \\
\text { Score per minute in the } 15 \\
\text { minute compulsory } \\
\text { working time }\end{array}$} & \multicolumn{3}{|c|}{ OLS Estimates } \\
\hline & (1) & (2) & (3) \\
\hline Single treatment & Ref. & Ref. & - \\
\hline All peer treatments & $\begin{array}{c}-0.037 \\
(0.175)\end{array}$ & - & - \\
\hline NCNF treatment & - & $\begin{array}{c}-0.055 \\
(0.199)\end{array}$ & Ref. \\
\hline NCF treatment & - & $\begin{array}{c}-0.115 \\
(0.238)\end{array}$ & $\begin{array}{c}-0.073 \\
(0.222)\end{array}$ \\
\hline CF treatment & - & $\begin{array}{c}0.064 \\
(0.195)\end{array}$ & $\begin{array}{c}0.126 \\
(0.173)\end{array}$ \\
\hline Male & $\begin{array}{c}0.086 \\
(0.127)\end{array}$ & $\begin{array}{c}0.104 \\
(0.125)\end{array}$ & $\begin{array}{l}0.211 * \\
(0.124)\end{array}$ \\
\hline Constant & $\begin{array}{c}1.528 * * * \\
(0.181)\end{array}$ & $\begin{array}{c}1.517^{* * *} * \\
(0.182)\end{array}$ & $\begin{array}{c}1.404 * * * \\
(0.131)\end{array}$ \\
\hline $\begin{array}{l}\mathrm{N} \\
\mathrm{R}^{2}\end{array}$ & $\begin{array}{c}104 \\
0.005\end{array}$ & $\begin{array}{c}104 \\
0.014\end{array}$ & $\begin{array}{c}78 \\
0.037\end{array}$ \\
\hline
\end{tabular}

Notes: All models are OLS regressions. Robust standard errors clustered at the pair level are in parentheses. Column (3) excludes data from the Single treatment.*** means significant at the 0.01 level, ** at the 0.05 level, and * at the 0.10 level. 


\section{Table D2. Determinants of total number of attempts per minute}

in the compulsory work time

\begin{tabular}{|c|c|c|c|c|c|c|c|}
\hline \multirow{2}{*}{$\begin{array}{l}\text { Dependent variable: } \\
\mathrm{Nb} \text { attempts per minute in } \\
\text { the } 15 \text { minute compulsory } \\
\text { working time }\end{array}$} & \multicolumn{6}{|c|}{ OLS Estimates } & \multirow[b]{2}{*}{ (7) } \\
\hline & (1) & (2) & (3) & (4) & (5) & (6) & \\
\hline Single treatment & Ref. & Ref. & & Ref. & Ref. & - & - \\
\hline All peer treatments & $\begin{array}{l}-0.012 \\
(0.168)\end{array}$ & - & - & $\begin{array}{l}-0.152 \\
(0.306)\end{array}$ & - & - & - \\
\hline NCNF treatment & - & $\begin{array}{l}-0.029 \\
(0.186)\end{array}$ & Ref. & - & $\begin{array}{l}-0.072 \\
(0.343)\end{array}$ & Ref. & - \\
\hline NCF treatment & - & $\begin{array}{l}-0.015 \\
(0.189)\end{array}$ & $\begin{array}{c}0.006 \\
(0.127)\end{array}$ & - & $\begin{array}{l}-0.332 \\
(0.323)\end{array}$ & $\begin{array}{l}-0.275 \\
(0.193)\end{array}$ & - \\
\hline $\mathrm{CF}$ treatment & - & $\begin{array}{c}0.008 \\
(0.185)\end{array}$ & $\begin{array}{c}0.044 \\
(0.136)\end{array}$ & - & $\begin{array}{c}0.044 \\
(0.319)\end{array}$ & $\begin{array}{c}0.143 \\
(0.211)\end{array}$ & - \\
\hline Ability & $\begin{array}{c}0.619^{* * *} \\
(0.104)\end{array}$ & $\begin{array}{c}0.618^{* * * *} \\
(0.106)\end{array}$ & $\begin{array}{c}0.640 * * * \\
(0.112)\end{array}$ & $\begin{array}{c}0.525^{* *} \\
(0.203)\end{array}$ & $\begin{array}{c}0.521^{* *} \\
(0.208)\end{array}$ & $\begin{array}{l}0.526^{* *} \\
(0.217)\end{array}$ & $\begin{array}{l}0.446^{* *} \\
(0.185)\end{array}$ \\
\hline Ability * peer treatments & - & - & - & $\begin{array}{c}0.135 \\
(0.218)\end{array}$ & - & - & - \\
\hline Ability * NCNF treatment & - & - & - & - & $\begin{array}{c}0.025 \\
(0.292)\end{array}$ & - & - \\
\hline Ability $*$ NCF treatment & - & - & - & - & $\begin{array}{c}0.347 \\
(0.220)\end{array}$ & $\begin{array}{c}0.327 \\
(0.236)\end{array}$ & - \\
\hline Ability $* \mathrm{CF}$ treatment & - & - & - & & $\begin{array}{l}-0.067 \\
(0.221)\end{array}$ & $\begin{array}{l}-0.114 \\
(0.247)\end{array}$ & - \\
\hline $\begin{array}{l}\text { Task-related } \\
\text { communication }\end{array}$ & - & - & - & - & - & - & $\begin{array}{c}0.401 * * \\
(0.156)\end{array}$ \\
\hline $\begin{array}{l}\text { Task unrelated } \\
\text { communication }\end{array}$ & - & - & - & - & - & - & $\begin{array}{c}-0.600 * * * \\
(0.155)\end{array}$ \\
\hline Male & $\begin{array}{l}-0.050 \\
(0.117)\end{array}$ & $\begin{array}{l}-0.047 \\
(0.119)\end{array}$ & $\begin{array}{c}0.026 \\
(0.098)\end{array}$ & $\begin{array}{l}-0.055 \\
(0.116)\end{array}$ & $\begin{array}{l}-0.028 \\
(0.121)\end{array}$ & $\begin{array}{c}0.061 \\
(0.098)\end{array}$ & $\begin{array}{l}-0.167 \\
(0.161)\end{array}$ \\
\hline Constant & $\begin{array}{c}1.373 * * * \\
(0.192) \\
\end{array}$ & $\begin{array}{c}1.372 * * * \\
(0.194) \\
\end{array}$ & $\begin{array}{c}1.284^{* * * *} \\
(0.107) \\
\end{array}$ & $\begin{array}{c}1.481 * * * \\
(0.283) \\
\end{array}$ & $\begin{array}{c}1.468 * * * \\
(0.287) \\
\end{array}$ & $\begin{array}{c}1.364 * * * \\
(0.165) \\
\end{array}$ & $\begin{array}{c}1.676^{* * * *} \\
(0.194) \\
\end{array}$ \\
\hline $\begin{array}{l}\mathrm{N} \\
\mathrm{R}^{2}\end{array}$ & $\begin{array}{c}104 \\
0.371\end{array}$ & $\begin{array}{c}104 \\
0.371\end{array}$ & $\begin{array}{c}78 \\
0.453\end{array}$ & $\begin{array}{c}104 \\
0.375\end{array}$ & $\begin{array}{c}104 \\
0.396\end{array}$ & $\begin{array}{c}78 \\
0.489\end{array}$ & $\begin{array}{c}26 \\
0.344\end{array}$ \\
\hline
\end{tabular}

Notes: All models are OLS regressions. Robust standard errors clustered at the pair level are in parentheses. Ability is the score per minute during the three-minute initial part. Columns (3) and (6) exclude data from the Single treatment. Column (7) only includes the data from the CF treatment.*** means significant at the 0.01 level, ** at the 0.05 level, and * at the 0.10 level. 


\section{Table D3. Determinants of productivity in the optional work time, conditional on continuing to work after the compulsory time}

\begin{tabular}{|c|c|c|c|c|c|c|c|}
\hline \multirow{2}{*}{$\begin{array}{l}\text { Dependent variable: } \\
\text { Score per minute in the } \\
\text { optional work time }\end{array}$} & \multicolumn{6}{|c|}{ OLS Estimates } & \multirow[b]{2}{*}{ (7) } \\
\hline & (1) & (2) & (3) & (4) & (5) & (6) & \\
\hline Single treatment & Ref. & Ref. & & Ref. & Ref. & - & - \\
\hline All peer treatments & $\begin{array}{c}0.187 \\
(0.176)\end{array}$ & - & - & $\begin{array}{c}0.241 \\
(0.275)\end{array}$ & - & - & - \\
\hline NCNF treatment & - & $\begin{array}{c}0.130 \\
(0.197)\end{array}$ & Ref. & - & $\begin{array}{c}0.329 \\
(0.361)\end{array}$ & Ref. & - \\
\hline NCF treatment & - & $\begin{array}{c}0.147 \\
(0.224)\end{array}$ & $\begin{array}{l}-0.008 \\
(0.216)\end{array}$ & - & $\begin{array}{c}0.014 \\
(0.328)\end{array}$ & $\begin{array}{l}-0.356 \\
(0.343)\end{array}$ & - \\
\hline $\mathrm{CF}$ treatment & - & $\begin{array}{c}0.271 \\
(0.243)\end{array}$ & $\begin{array}{c}0.145 \\
(0.230)\end{array}$ & - & $\begin{array}{c}0.295 \\
(0.326)\end{array}$ & $\begin{array}{c}0.007 \\
(0.341)\end{array}$ & - \\
\hline Ability & $\begin{array}{c}0.588 * * * \\
(0.105)\end{array}$ & $\begin{array}{c}0.590 * * * \\
(0.108)\end{array}$ & $\begin{array}{c}0.532 * * * \\
(0.122)\end{array}$ & $\begin{array}{c}0.624 * * * \\
(0.191)\end{array}$ & $\begin{array}{c}0.621 * * * \\
(0.197)\end{array}$ & $\begin{array}{l}0.375^{*} \\
(0.206)\end{array}$ & $\begin{array}{c}0.323 \\
(0.279)\end{array}$ \\
\hline Ability * peer treatments & - & - & - & $\begin{array}{l}-0.052 \\
(0.218)\end{array}$ & - & - & - \\
\hline Ability * NCNF treatment & - & - & - & - & $\begin{array}{l}-0.206 \\
(0.288)\end{array}$ & - & - \\
\hline Ability * NCF treatment & - & - & - & - & $\begin{array}{c}0.139 \\
(0.227)\end{array}$ & $\begin{array}{c}0.358 \\
(0.245)\end{array}$ & - \\
\hline Ability $* \mathrm{CF}$ treatment & - & - & - & & $\begin{array}{l}-0.019 \\
(0.312)\end{array}$ & $\begin{array}{c}0.146 \\
(0.325)\end{array}$ & - \\
\hline $\begin{array}{l}\text { Task-related } \\
\text { communication }\end{array}$ & - & - & - & - & - & - & $\begin{array}{l}-0.208 \\
(0.475)\end{array}$ \\
\hline $\begin{array}{l}\text { Task unrelated } \\
\text { communication }\end{array}$ & - & - & - & - & - & - & $\begin{array}{l}-0.607 \\
(0.392)\end{array}$ \\
\hline Male & $\begin{array}{l}-0.238 \\
(0.155)\end{array}$ & $\begin{array}{l}-0.229 \\
(0.158)\end{array}$ & $\begin{array}{l}-0.053 \\
(0.168)\end{array}$ & $\begin{array}{l}-0.236 \\
(0.155)\end{array}$ & $\begin{array}{l}-0.222 \\
(0.158)\end{array}$ & $\begin{array}{l}-0.042 \\
(0.164)\end{array}$ & $\begin{array}{l}-0.219 \\
(0.272)\end{array}$ \\
\hline Constant & $\begin{array}{c}1.505^{* * *} \\
(0.196) \\
\end{array}$ & $\begin{array}{c}1.498 * * * \\
(0.200)\end{array}$ & $\begin{array}{c}1.591 * * * \\
(0.191) \\
\end{array}$ & $\begin{array}{c}1.464 * * * \\
(0.248) \\
\end{array}$ & $\begin{array}{c}1.459 * * * \\
(0.255) \\
\end{array}$ & $\begin{array}{c}1.732 * * * \\
(0.269) \\
\end{array}$ & $\begin{array}{c}2.357 * * * \\
(0.288) \\
\end{array}$ \\
\hline $\mathrm{N}$ & 89 & 89 & 67 & 89 & 89 & 67 & 25 \\
\hline $\mathrm{R}^{2}$ & 0.246 & 0.251 & 0.214 & 0.246 & 0.264 & 0.233 & 0.320 \\
\hline
\end{tabular}

Notes: All models are OLS regressions. Robust standard errors clustered at the pair level are in parentheses. Ability is the score per minute during the three-minute initial part. Columns (3) and (6) exclude data from the Single treatment. Column (7) only includes the data from the CF treatment.*** means significant at the 0.01 level, ** at the 0.05 level, and * at the 0.10 level. 


\section{APPENDIX E. PROCEDURE FOR COMPARING THE WITHIN-PAIR AND BETWEEN-PAIR DIFFERENCES IN THE QUITTING TIME BETWEEN THE SINGLE AND THE PEER TREATMENTS}

To compare the within-pair and between-pair standard deviations (S.D.) in the peer treatments and in the Single treatment, we generated and selected randomly 30,000 configurations of 13 hypothetical pairs formed with the 26 participants of the Single treatment. In fact, the total number of possible configurations of 13 pairs is $7,905,853,580,625(25 * 23 * 21 * \ldots * 1)$, but for obvious computing time constraints, we have selected only an arbitrary fraction of these hypothetical pairs. We believe, however, that this number of observations provides sufficient power to test our hypotheses.

In each hypothetical pair, we first compute the within-pair S.D. given by the absolute value of the difference in the quitting time expressed in seconds between the two co-workers $\left((a b s)\left(t_{1 j^{-}}\right.\right.$ $t_{2 j}$ ), where $t_{i j}$ represents the quitting time of worker $i$ in pair $j$ ), divided by the square root of 2 . We then compute the mean within-pair S.D. for each configuration. Figure 2a plots the Kernel density of the mean within-pair S.D. for the 30,000 configurations. Next, we calculate the within-pair S.D. for each actual pair in each peer treatment. Thus, for each peer treatment, we obtain one mean value of the within-pair S.D. that is represented by a vertical line in Figure 2a.

We proceed similarly for the analysis of the between-pair S.D; we calculate the mean quitting time in each hypothetical pair of the Single treatment $\left.\left(\left(t_{l j}+t_{2 j}\right) / 2\right)\right)$ and then for each of the 30,000 configurations we compute the S.D. between pairs. Figure $2 \mathrm{~b}$ displays the Kernel density of the between-pair S.D. for the 30,000 configurations. Next, we calculate the mean quitting time for each actual pair and the corresponding S.D. of these values. Thus, for each peer treatment we obtain one value of the between-pair S.D. that is represented by a vertical line in Figure $2 b$. 
APPENDIX F. KAPLAN-MEIER SURVIVAL ESTIMATES OF THE QUITTING TIME BY TREATMENT

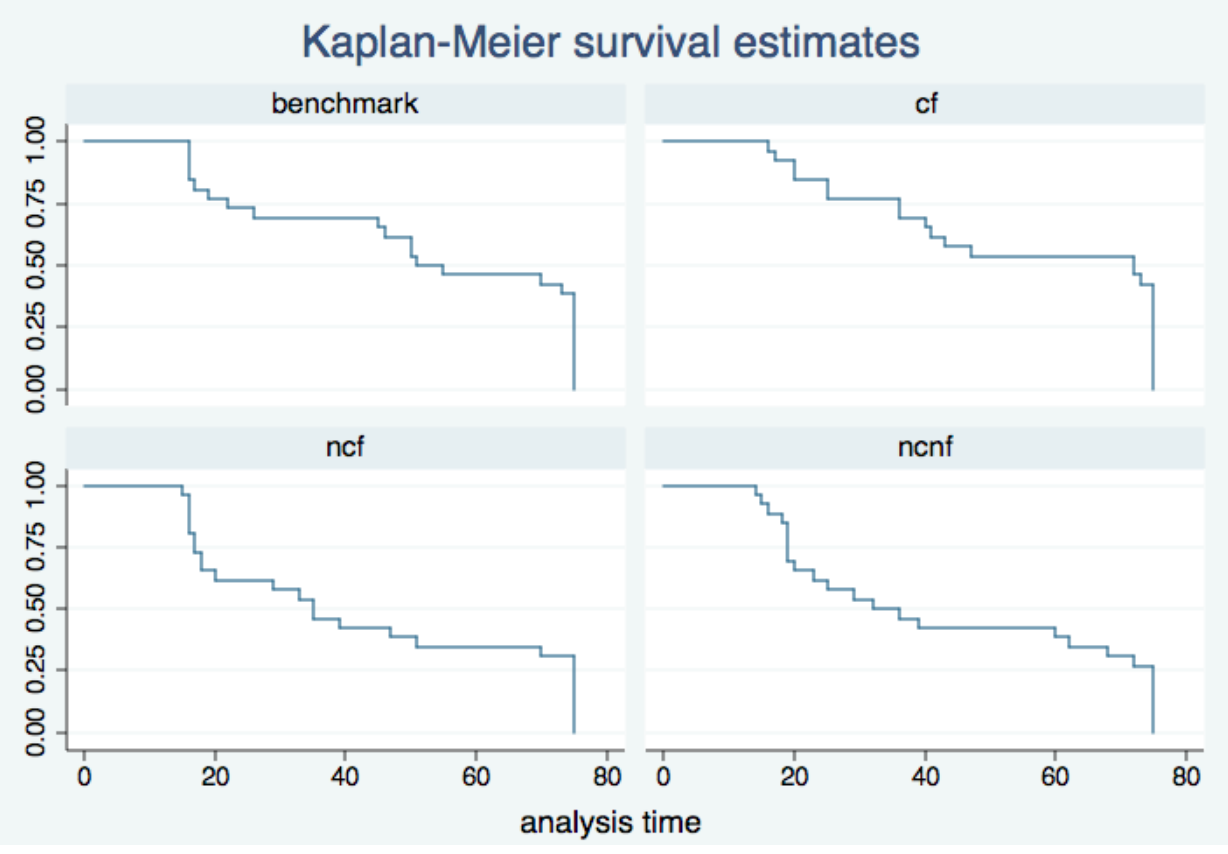

Figure 1F. Survival estimates, by treatment 


\section{APPENDIX G. TABLE G1: DETERMINANTS OF WORKERS CONTINUING TO WORK PROBIT (NON-PARAMETRIC HAZARD) ESTIMATES}

\begin{tabular}{|c|c|c|c|c|c|}
\hline Treatments & $\begin{array}{c}\text { Single } \\
\text { and NCNF } \\
(1)\end{array}$ & $\begin{array}{c}\text { Single } \\
\text { and NCF } \\
(2)\end{array}$ & $\begin{array}{c}\text { Single } \\
\text { and CF } \\
(3)\end{array}$ & $\begin{array}{l}\mathrm{NCNF}, \\
\mathrm{NCF} \text { and } \\
\mathrm{CF} \\
(4)\end{array}$ & $\begin{array}{c}\text { Marginal } \\
\text { Effects } \\
(4 \mathrm{M})\end{array}$ \\
\hline Constant & $\begin{array}{c}0.969 * * \\
(0.440)\end{array}$ & $\begin{array}{c}0.940 * * \\
(0.464)\end{array}$ & $\begin{array}{c}1.601 * * \\
(0.512)\end{array}$ & $\begin{array}{c}1.187 * * * \\
(0.384)\end{array}$ & \\
\hline Minute & $\begin{array}{l}0.059 * * \\
(0.024)\end{array}$ & $\begin{array}{l}0.053 * * \\
(0.025)\end{array}$ & $\begin{array}{c}0.014 \\
(0.027)\end{array}$ & $\begin{array}{c}0.032 \\
0.022)\end{array}$ & $\begin{array}{l}0.1 \% \\
(0.1 \%)\end{array}$ \\
\hline $\begin{array}{l}\text { Minute-Squared } \\
\text { (= est. times 100) }\end{array}$ & $\begin{array}{c}-0.062 * * \\
(0.028)\end{array}$ & $\begin{array}{l}-0.054^{*} \\
(0.029)\end{array}$ & $\begin{array}{l}-0.007 \\
(0.030)\end{array}$ & $\begin{array}{l}-0.023 \\
(0.028)\end{array}$ & $\begin{array}{c}0.0 \% \\
(0.1 \%)\end{array}$ \\
\hline $\begin{array}{l}\text { Ability } \\
\text { (score in initial } \\
\text { period) }\end{array}$ & $\begin{array}{c}0.007 \\
(0.032)\end{array}$ & $\begin{array}{c}0.041 \\
(0.034)\end{array}$ & $\begin{array}{c}0.038 \\
(0.035)\end{array}$ & $\begin{array}{c}0.010 \\
(0.031)\end{array}$ & $\begin{array}{c}0.04 \% \\
(0.01 \%)\end{array}$ \\
\hline NCNF & $\begin{array}{c}-0.135 \\
(0.148)\end{array}$ & & & & \\
\hline $\mathrm{NCF}$ & & $\begin{array}{l}-0.126 \\
(0.150)\end{array}$ & & & \\
\hline $\mathrm{CF}$ & & & $\begin{array}{c}0.144 \\
(0.153)\end{array}$ & $\begin{array}{c}0.265^{* *} \\
(0.132)\end{array}$ & $\begin{array}{c}1.03 \% \\
(0.48 \%)\end{array}$ \\
\hline $\begin{array}{l}\text { Log-likelihood } \\
\mathrm{N}\end{array}$ & $\begin{array}{c}-157.66 \\
1,702\end{array}$ & $\begin{array}{c}-156.33 \\
1,677\end{array}$ & $\begin{array}{c}-139.76 \\
1,955\end{array}$ & $\begin{array}{l}-227.75 \\
2,493\end{array}$ & $\begin{array}{c}-227.75 \\
2,493\end{array}$ \\
\hline
\end{tabular}

Notes: Minute and Minute ${ }^{2}$ are the times during the optional work period (minutes 15 to 75 ). Robust standard errors are clustered at the pair level. *** means significant at the 0.01 level, ** at the 0.05 level, * at the 0.10 level. 